University of Rhode Island

DigitalCommons@URI

Open Access Master's Theses

1971

\title{
The Biosynthesis of Carotenoids in the Tomato Fruit
}

Leoncio Condez Raymundo

University of Rhode Island

Follow this and additional works at: https://digitalcommons.uri.edu/theses

\section{Recommended Citation}

Raymundo, Leoncio Condez, "The Biosynthesis of Carotenoids in the Tomato Fruit" (1971). Open Access Master's Theses. Paper 2034.

https://digitalcommons.uri.edu/theses/2034

This Thesis is brought to you for free and open access by DigitalCommons@URI. It has been accepted for inclusion in Open Access Master's Theses by an authorized administrator of DigitalCommons@URI. For more information, please contact digitalcommons-group@uri.edu. 
THE BIOSYNTHESIS OF CAROTENOIDS IN

THE. TOMATO FRUIT

BY

LEONCIO CONDEZ RAYMUNDO

A THESIS SUBMITTED IN PARTIAL FULFILLMENT OF THE

REQUIREMENTS FOR THE DEGREE OF

DOCTOR OF PHILOSOPHY

IN

BIOLOGICAL SCIENCES

(FOOD AND RESOURCE CHEMISTRY)

UNIVERSITY OF RHODE ISLAND

1971 


\section{ABSTRACT}

Detached fruits of the "lutescent", high-beta and ghost tomatces were treated with either dimethyl sulfoxide (DMSO) or 2-i4-chlorophenijithio)-triethylamine hydrochloride (CPTA) to study the biosynthetic origin of $\beta$-carotene in the tomato fruit. When mature "lutescent" tomato fruits (Stage 3) were treated with DMSO the synthesis of the acyclic carotenoids phytoene, phytofluene, $\tau_{3}$-carotene and lycopene was inhibited; the synthesis of $\beta$-carociene and the other cyclic carotenes was not affected. In less mature fruits (Stage 2), however, DMSO treatment inhibited the synthesis of both acyclic and cyclic carotenoids.

The synthesis of all the carotenoid fractions in high-beta fruits treated with DMSO at the mature green stage was inhibited. The highbeta fruit was found to contain increased levels of R-zeacarotere. Its synthesis, along with that of $\gamma$ - and $\beta$-carotenes, decreased in the presence of DMSO. It was concluded, therefore, that the $\beta$-carotene fraction formed during ripening of the high-beta fruit is probably formed by cyclization of neurosporene to $\beta$-zeacarotene and not by cyclization of iycopene. It was suggested that the $\mathrm{B}^{+} \mathrm{B}, \mathrm{mo}_{\mathrm{B}}{ }^{+} \mathrm{mo}_{\mathrm{B}}$ genes probably control the balance between lycopene and $\beta$-carotene syitheses via a repressorefrector molecule interaction.

Total carotenoid accumulation in ripened "lutescent" and high-beta tonato fruits was reduced by DMSO treatment. CPTA did not affect carotenogenes is in the grost tomato mutant. The rasults suggest that CPTA can exert its influence only in an already existing pathway and will not overcome inhibition imposed by genetic mutation. In contrast, lycopene 
content increased fifteen-fold in the high-beta fruit treated with CFTA. The increase in the lycopene concentration was accompanied by a general increase in the level of the other acyclic carotenoids in the fruit. The $\beta$-zeacarotene, $\gamma$-carotene and $\beta$-carotene contents of the fruit decreased concomittantly. Total carotenoid accumulation in the high-beta fruit was reduced by CPTA.

A re-evaluation of the results of earlier work on the genetics of the inheritance of tomato fruit color and tomato plastid structural siudies in conjunction with the findings in this study indicate that (1) the additional level of B-carotene in the high-beta fruit may be formed mainly via the $\beta$-zeacarotene route, (2) the chloroplast $\beta$-carotene is probably produced tinrough a biosynthetically independent pathway from the carotenes of the chromoplast, and (3) the additional $\beta$-carotene fraction synthesized during ripening of the normal red tomato genotype is probably formed by a "carry-over" pathway from the green fruit.

A contaminant of the $\beta$-carotene fraction of the Tangerine tomato fruit extract was isolated and identified as a poly-cis isomer of $\zeta$-carotene. The ripening fruit contains $0.8 \mathrm{ug} / \mathrm{g}$ dry weight of the pigment. The possible role of the poly-cis $\zeta$-carotene in the biosynthes is of poly-cis carotenes is discussed. 


\section{PREFACE}

The thesis was written to conform with the format outlined by the Graduate School for the Manuscript Thesis Plan.

Part I of this thesis was published in Phytochemistry, volume 9, pages 1239-1245 (1970); part II has been submitted to The Biochemical Journal, London. The data on the effect of CPTA on Phycomyces were furnished by Dr. C. O. Chichester's laboratory but were included in the second manuscript of the thesis because of the similarity of the response of the two carotenogenic systems to the chemical inhibitor and because the manuscript was submitted in this form. The third manuscript has been accepted for publication in Phytochemistry. 


\section{ACKNOWLEDGEMENTS}

I owe much of whatever significant contribution this investigation has made to the area of carotenoid research to my adviser, Dr. Kenneth L. Simpson. It was such a pleasure to work for him that the seemingly intolerable task of literally working in the dark turned out to be a very intriguing one. I consider it a very rare opportunity, indeed, to have conducted all my graduate research work under his direction. For these and for his faith in my ability, I wish to express my profound gratitude to him.

I would also like to thank Dr. Luke S. Albert for his comments on the thesis and for his excellent course in Advanced Plant Physiology which greatly influenced my deductive reasoning and rationalization. To Dr. Albert E. Griffiths, I wish to extend my sincere appreciation for his help in growing the experimental plants used throughout this investigation, and for reviewing the final draft of this thesis and the manuscripts. In some instances, I did not agree with his comments and I am largely responsible for all the errors which are found in the text. I would also like to thank Dr. C. 0. Chichester for serving in my committee despite his unbelievably busy schedule.

I am also personally indebted to Drs. Alberto and Ascunia Feliciano and their daughter Eva, for their patience, kindness and understanding, listening to my countless miseries and frustrations. 
To my parents, Leoncio Bartolome and Elpidia Condez Raymundo. 


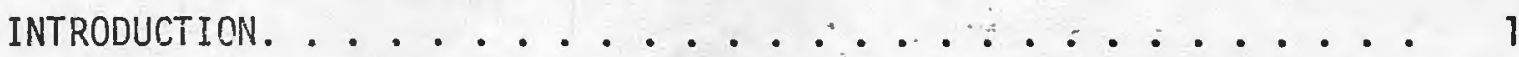

PART I. BIOSYNTHESIS OF CAROTENOIDS IN THE TOMATO FRUIT. . .

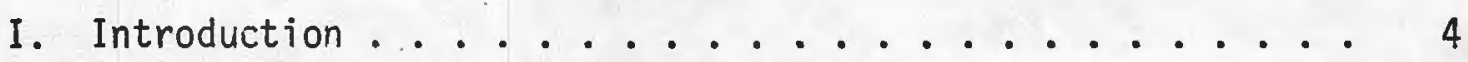

II. Results and Discussion ............. 8

III. Experimental . . . . . . . . . . 19

Solvents and chromatographic adsorbents. . . . . 19

Fruit. ........................ 19

Treatment with DMSO...................... 19

Pigment extraction and chromatography. . . . . 19

Pigment identification .............. 21

IV. Acknowledgements ................. 21

PART II. THE EFFECT OF 2-(4-CHLOROPHENYLTHIO)-TRIETHYLAMINE HYDROCHLORIDE (CPTA) ON CAROTENE FORMATION IN PHYCOMYCES AND DETACHED TOMATO

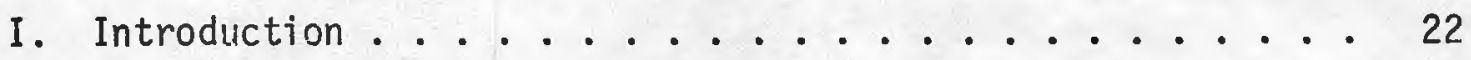

II. Experimental Methods .............. 23

III. Results..................... 25

IV. Acknowledgements ............... 27

v. References................... 29

PART III. THE ISOLATION OF A POLY-CIS $\zeta$-CAROTENE FROM THE TANGERINE TOMATO

I. Introduction ........................ 30

II. Results and Discussion ................. 31 
III. Experimental....................... 38

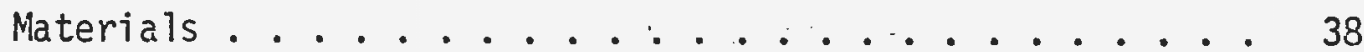

Pigment extraction and purification ......... 38

Absorption spectra. ..................... 39

IV. Acknowledgements. . . . . . . . . . . . 39 APPENDIX

I. IN RETROSPECT ...................... 40

A. The Protective Function of Carotenoids Against

Photosensitized Oxidation ......... 40

B. The Genetics of the Inheritance of Chromoplast

Carotenoids in the Tomato Fruit ......... 44

C. Biosynthesis of Carotenoids .......... 49

II. MATERIALS AND METHODS .................... 59

A. The Plant Materials ........... 59

B. The Chemicals.............. 60

C. General Procedure for Qualitative Analysis of

Carotenoid Pigments of the "Lutescent", High-beta

and Ghost Tomatoes. . . . . . . . . . . . 61

1. Pigment Extraction........... 61

2. Chromatographic Separations ........ 62

3. Purification Procedures .......... 63

D. Extraction and Chromatographic Procedures for the

Isolation of Poly-cis $\zeta$-Carotene from the Tangerine

Tomato................ 65 
PAGE

E. Pigment Identification. .......... 66

F. Spectrophotometric Analysis ......... 66

G. Iodine Catalysis............... 67

III. DISCUSSION. ...................... 68

BIBLIOGRAPHY ...................... 76 
TABLE

1.1. Effect of DMSO on carotenoid synthes is in ripening stage 3 fruits of the lutescent tomato......... 9

1.2. Effect of DMSO on carotenoid synthesis in ripening stage 2 fruits of the lutescent tomato......... 11

I.3. Effect of DMSO on the biosynthesis of carotenoids in the high-beta tomato fruit. ............ 12

I.4. Genotypes of the low-beta (normal red), intermediate-beta, and high-beta tomato strains........... 16

II.1. Carotenoid distribution in Phycomyces blakesleeanus and in detached tomato fruits treated with CPTA. ....... 28

III.1. $\lambda_{\max }$ of the poly-cis $\zeta$-carotene and some natural and synthetic

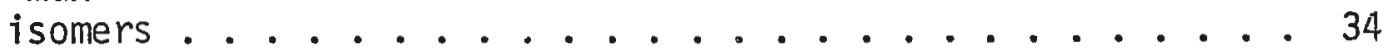

APPENDIX

TABLE

1. Genctypes of tomato fruit color mutants ..........446 


\section{LIST OF FIGURES}

FIGURE

III.1. Specific extinction curves of poly-cis $\zeta$-carotene, in petroleum ether: (a) fresh solution; (b) mixture of stereoisomers after catalysis by iodine; and (c) mixture of stereoisomers after catalysis of al1-trans

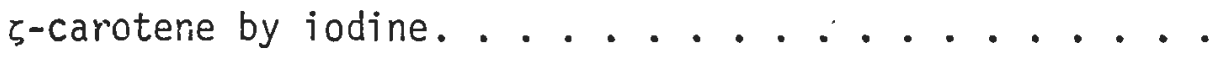

III.2. Possible pathways leading to the formation of proTycopene. . . . . . . . . . . . . .

1. Modified scheme for the biosynthesis of geranylgeranyl pyrophosphate .............. . . 50

2. The biosynthesis of acyclic carotenoids ........ 51

3. Alternative pathways for the biosynthes is of cyclic

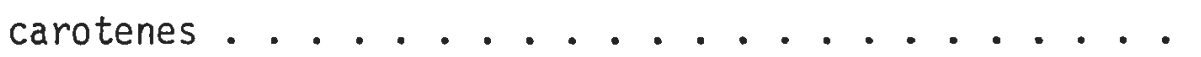

4. The proposed scheine for compartmentalization of terpenoid biosynthesis in higher plants . . . . . . . . .

5. A scheme for the biosynthesis of lycopene and the cyclic carotenes in the tomato fruit........... 
INTRODUCTION 
Carotenoids are widely distributed in both the plant and the animal kingdoms. However, only plants are believed capable of synthesizing carotenoids de novo. Since carotenoids are precursors of Vitamin A required by animals for their growth and survival, animals rely on plants to fulfill their requirement for this vitamin. Plants, on the other hand, synthesize carotenoids primarily to protect their photosynthetic apparatus against photoinduced destruction catalyzed by their own chlorophyll or other light-absorbing compounds in the presence of oxygen. Only those molecules which have $\beta$-ionone ring possess provitamin A activity. Because the $\beta$-carotene molecule contains two such rings, it has theoretically the highest provitamin A activity among the naturally occurring carotenoids. $\beta$-Carotene is present in all photosynthetic tissues. Its role in these tissues, however, has not been clearly defined.

On ripening large amounts of carotenoids accumulate in the tomato fruit, in addition to the $\beta$-carotene and $i$ ts oxygenated derivatives found in the immature green fruit. The kind and amount of carotenoid pigment synthesized during the transformation is largely dependent on the particular genotype of the plant with respect to fruit color. Temperature and light exert the most profound effects on carotenoid distribution in the tomato fruit among the various environmental factors affecting plant growth.

The more unsaturated carotenoids are formed by tine sequential desaturation of phytoene. This compound is colorless because it has only three conjugated carbon-to-carbon double bonds. As the chromophore is 
extended the molecule absorbs light at proportionately longer wavelengths. The absorbance falls in the visible region when seven double bonds are in conjugation. Thus the polyene is colored. Theoretically, the acyclic carotenoid molecule can have fifteen carbon-to-carbon double bonds in conjugation. Such a molecule will absorb light in the green region of the spectrum and therefore will impart a purple color.

The color intensity of the pigment is reduced by bending of the chromophore which is caused by either trans $\rightarrow$ cis rearrangement or by cyclization of the molecule. Spectroscopically, the absorption maxima are shifted toward the shorter wavelength. The absorption spectrum shows a loss of fine structure in the fundamental region with the concurrent appearance of cis-peak(s) in the near-ultraviolet region (Zechmeister, 1962).

The carotenoid molecule is extremely sensitive to trans $\rightarrow$ cis rearrangement because of the multiconjugated system. A large number of geometric isomers is, therefore, possible. Of the eleven conjugated double bonds in the lycopene molecule, however, only seven can readily undergo such rearrangement (Zechmeister, 1962). These are the methy 1ated double bonds and the central double bond. Steric hindrance created by the overlapping of the neighboring hydrogen and methyl groups in the other positions reduces the probability of trans $\rightarrow$ cis rearrangement in the unmethylated positions (Pauling, 1939). Consequently, when an a11-trans carotenoid is subjected to stereoisomerization, the formation of the unhindered cis isomers will predominate over that of the hindered forms. 
The more unsaturated carotenoids are formed from phytoene. The immediate precursor for the cyclic carotenes, however, is still debatable. Structurally, lycopene is the most closely related acyclic carotenoid to the cyclic carotenes. However, high temperature and a number of chemicals can inhibit lycopene synthesis in the tomato fruit preferentially without affecting $\beta$-carotene synthesis. A precursorproduct relationship between the two pigments is therefore considered highly unlikely. To circumvent the objection, an alternate pathway to the cyclic carotenes was proposed (Porter and Anderson, 1962) which does not involve lycopene. In this scheme, cyclization starts at neurosporene with $\beta$-zeacarotene as the intermediate.

It is the purpose of this investigation to attempt to delineate the biosynthetic pathway for $\beta$-carotene in the tomato fruit using the chemical inhibitors dimethyl sulfoxide (DMSO) and 2-(4-chlorophenylthio)-triethylamine hydrochloride (CPTA). 
PART I. BIOSYNTHESIS OF CARÓTENOIDS IN THE TOMATO FRUIT 


\title{
BIOSYNTHESIS OF CAROTENOIDS IN THE TOMATO FRUIT
}

\author{
Leoncio C. Raymundo, Albert E. Griffiths* and \\ Kenneth L. Simpson \\ Departments of Agricultural Chemistry and Horticulture* \\ University of Rhode Island \\ Kingston, Rhode Is I and 02881 , U.S.A.' \\ Abstract--The effect of DMSO on the biosynthesis of \\ carotenoids in detached fruits of the "lutescent" \\ tomato harvested at different stages of maturity was \\ studied. DMSO inhibited the synthesis of both the \\ acyclic and cyclic carotenoids in fruits treated prior \\ to the lutescent stage. When more mature fruits were \\ used the $\beta$-carotene content was not affected by DMSO \\ while the levels of all other carotenoids examined \\ significantly decreased. The pigment distribution in \\ the fruit of the high-beta tomato genetic line was also \\ studied. The high-beta fruit contained more $\beta$-zea- \\ carotene and $\gamma$-carotene than the fruit of the normal \\ red tomato 'Summer Sunrise' of comparable ripeness. \\ Treatment with DMSO inhibited the synthesis of both \\ the acyclic and cyclic carotenoids in the high-beta \\ tomato fruit. The possible role of the $B^{+} / B, \mathrm{mo}_{B}+/ \mathrm{mo}_{B}$ \\ genes is discussed.
}

\section{INTRODUCTION}

It is now generally accepted that the more unsaturated carotenoids are formed by dehydrogenation of the phytoene molecule. However, the point of cyclization is still ambiguous. The modified scheme proposed by Porter and Anderson ${ }^{2}$ accommodated the evidence obtained from carotenogenic systems other than the tomato fruit, where lycopene does not appear to be an intermediate in the biogenes is of $\beta$-carotene. ${ }^{3-6}$

TContribution number 1331 of the Rhode Island Agricultural Experiment Station. ${ }_{3}^{2}$ J. W. Porter and D. G. Anderson, Arch. Biochem. Biophys. 97, 520 (1962).

3 B. H. Davies, Biochem. J. 80, 48p (1961).

B. H. Davies, J. Vilioutreix, R.J.H. Williams and T. W. Goodwin, Biochem. J. $589,96 p(1963)$.

5 T. W. Gcodwin, Chemistry and Biochemistry of Plant Pigments, (Edited by

6. W. Goodwin), p. 143. Academic Press, New York (1965).

6. L. Simpson, T.0.M. Nakayama and C. 0. Chichester, J. Bacterio?. 88, 1688 (1964). 
This scheme proposes that $\beta$-carotene is formed by cyclization of both lycopene $\rightarrow \gamma$-carotene $\rightarrow \beta$-carotene, and neurosporene $\rightarrow \beta$-zeacarotene $\rightarrow \gamma$-carotene $\rightarrow \beta$-carotene.

It was originally the result of genetic studies ${ }^{7-9}$ of the inheritance of carotenoids in the tomato fruit which led Porter and Lincoln ${ }^{10}$ to suggest that $\beta$-carotene is formed from lycopene. The conversion of lycopene to $\beta$-carotene by leaf chloroplasts, ${ }^{11-14}$ tomato fruit plastids, $12-14$ and a soluble extract of tomato fruit plastids ${ }^{13}$ has been reported.

In the high-beta selection described by Porter and Lincoln, 10 the loss of lycopene was accompanied by the accumulation of a large amount of $\beta$-carotene in the fruit. The implication was that the $\beta$-carotene was derived from 1ycopene. ${ }^{7}$ However, Tomes ${ }^{15}$ and Tomes et al. ${ }^{16}$ found that the $\beta$-carotene in the high-beta tomato is inhibited by ripening at temperatures above $30^{\circ}$. In the normal red parent as well as in other normal red lines ${ }^{15-17}$ the $\beta$-carotene fraction is not sensitive to high tempera-

7 G. W. Kohler, R. E. Lincoln, J. W. Porter, F. P. Zscheile, R. M. Caldwell, 8. H. Harper and W. Silver, Bot. Gaz. 109, 219 (1947).

8G. Mackinney and J. A. Jenkins, Proc. Nat. Acad. Sci. U.S. 35, 284 (1949). 10 R. E. Lincoln and J.W. Porter, Genetics 35, 206 (1950).

10 J. W. Porter and R. E. Lincoln, Arch. Biochem. Biophys. 27, 390 (1950). 11 K. Decker and H. Uehleke, Hoppe-Seyl. Z. physiol. Chem. $\frac{323}{23}, 61$ (1961); $12 \mathrm{~L}$. W. Wells, W. J. Schelble and J. W. Porter, Fed. Proc. 23,426 (1964). ${ }^{13}$ S. Kushwaha, C. Subbarayan, D. A. Beeler and J.W. Porter, J. Biol. Chem. $14 \frac{244}{4}, 3635$ (1969).

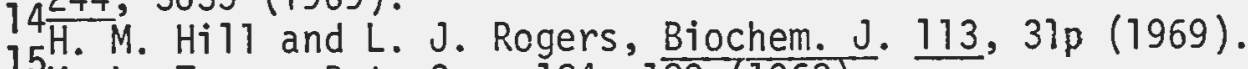

$15 \mathrm{M}$. L. Tomes, Bot. Gaz. 124, 180 (1963).

16 M. L. Tomes, F. W. Quackenbush and T. E. Kargl, Bot. Gaz. 117, 248 (1956).

17. W. Goodwin and M. Jamikorn, Nature 170, 104 (1952). 
ture. Tomes ${ }^{15}$ suggested that there may be two types of $\beta$-carotene in the tomato fruit--one type being synthesized through lycopene which is sensitive to high temperature, the other through some pathway not involving lycopene which is not affected by high temperature.

It is also possible to inhibit lycopene synthesis in ripening fruit of the normal red tomato without affecting $\beta$-carotene formation by means of such diverse agents as irradiation ${ }^{18}$ and treatment with dimethy 1 sulfoxide (DMSO). ${ }^{19}$ The selective inhibitory effect of DMSO on the acyclic carotenoids of ripening normal red tomato ${ }^{19}$ was explained on the basis of two possible modes of action:

(1) That a compartmentalization of similar enzymes exists in the toma to fruit and that DiMSO affects a key enzyme but not its isoenzyme.

(2) That the enzyme system for the cyclic carotenes is formed early in the development of the fruit, whereas that of the acyclic carotenes is formed later and that DMSO in some way inhibits the latter system.

In order to test the second hypothesis an accurate determination of fruit maturity would be necessary. Critical determinations of the state of maturity of the green "Summer Sunrise" tomato are difficult. The "mature green" fruit of the "lutescent" tomato, however, is nearly devoid of chlorophyll so that carotene synthesis can be followed visually. The "Tutescent" fruit normally gces from white to yellow to red.

If the additional level of $\beta$-carotene in the high-beta tomato is formed by cyclization of neurosporene $\rightarrow \beta$-zeacarotene $\rightarrow \gamma$-carotene,

\footnotetext{
${ }_{19}$ E. E. Burns and N. W. Desrosier, Food Tech. 11, 313 (1957).

19. C. Raymundo, A. E. Griffiths and K. L. Simpson, Phytochem. 6, 1527 (1967).
} 
one might expect to find increased levels of $\beta$-zeacarotene and $\gamma$-carotene. The $\gamma$-carotene content of the tomato fruit has been found to increase in the presence of the $\mathrm{BB}$ gene. ${ }^{15,20}$ B-Zeacarotene has only been isolated from the normal red tomato ${ }^{19}$ and has not been reported in the high-beta tomato.

The objectives of this study were (1) to determine the effect of DMSO on carotenoid synthesis in the "lutescent" tomato fruit treated at different stages of maturity, (2) to determine the effect of DMSO on carotenoid synthesis in detached, mature green, high-beta tomato fruit, and (3) to attempt to del ineate the biosynthetic pathway for $\beta$-carotene in the tomato fruit.

$\overline{20}$ M. L. Tomes, F. W. Quackenbush and M. McQuistan, Genetics 39, 810 (1954). 


\section{RESULTS AND DISCUSSION}

The tomato fruits were harvested and separated into 4 stages of maturity. The following criteria were used:

Stage 1. White; greenish around the stem-end.

Stage 2. Primarily white; slightly lutescent around the stem-end.

Stage 3. Lutescent; slight internal pink coloration.

Stage 4. Full yellow; externally visible red coloration at the blossom end and throughout the ceriter of the fruit.

Preliminary ripening experiments using detached Stage 1 fruits resulted in highly variable pigmentation which was sufficiently great to preclude the use of Stage 1 fruits in this study. Stage 4 fruits shoved less difference in color when compared with the control than Stages 2 and 3 after treatment with DMSO.

The kinetics of carotenoid synthesis in detached fruits of the "lutescent" tomato are shown in Tables 1 and 2 . The formatior, of $\beta$-carotene appears complete after 3 days in fruits that were harvested at Stage 3 (Table 1). Lycopene started to accumulate rapidly on the third day of ripening and reached the maximum level on the fifth day.

Treatment with DMSO inhibited the synthesis of the acyclic carctenoids phytoene, phytofluene, $\zeta$-carotene and lycopene (Table 1). The level of inhibition is about the same order of magnitude as was reported for the normal red tomato. ${ }^{19}$ Synthesis of the cyclic carotenes was not as drastically affected as the synthesis of the acyclic carotenoids. $\beta$-Carotene synthesis was not significantly different in the control and 
Table I. 1. Effect of DMSO on carotenoid synthesis in ripening Stage 3 fruits of the "lutescant", tomato.*

POLYENE

$\mu \mathrm{g} / \mathrm{g}$ dry weight Days

\begin{tabular}{|c|c|c|c|c|c|c|}
\hline & 0 & 2 & 3 & 4 & 5 & 6 \\
\hline Phytoene & $\frac{0.3}{0}$ & $\frac{4.7}{0}$ & $\frac{7.9}{2.4}$ & $\frac{19.8}{0.5}$ & $\frac{23.9}{4.0}$ & $\frac{55.9}{4.0}$ \\
\hline Phytofluene & $\frac{0.3}{\text { Trace }}$ & $\frac{1.5}{0.7}$ & $\frac{9.8}{1.5}$ & $\frac{12.3}{1.9}$ & $\frac{28.7}{2.5}$ & $\frac{39.5}{2.2}$ \\
\hline$\zeta$-Carotene & $\frac{--}{--}$ & $\overline{--}$ & $\frac{--}{--}$ & $\frac{1.22}{\text { Trace }}$ & $\frac{2.3}{0.3}$ & $\frac{4.2}{\text { Trace }}$ \\
\hline Lycopene & $\frac{4.9}{0}$ & $\frac{62.4}{26.3}$ & $\frac{118.8}{21.1}$ & $\frac{235.1}{24.9}$ & $\frac{402.0}{33.0}$ & $\frac{334.5}{48.7}$ \\
\hline$\beta$-Zeacarotene & $\frac{0.4}{0.2}$ & $\frac{0.7}{0.9}$ & $\frac{0.7}{0.9}$ & $\frac{--+}{0.6}$ & $\frac{1.4}{0.7}$ & $\frac{--+}{0.9}$ \\
\hline$\gamma$-Carotena & $\frac{0.3}{\text { Trace }}$ & $\frac{2.8}{2.1}$ & $\frac{5.4}{1.1}$ & $\frac{8.1}{2.5}$ & $\frac{9.7}{3.6}$ & $\frac{7.7}{2.1}$ \\
\hline$\beta$-Carotene & $\frac{27.7}{16.8}$ & $\frac{49.5}{42.1}$ & $\frac{60.4}{52.6}$ & $\frac{59.6}{51.0}$ & $\frac{64.7}{63.9}$ & $\frac{59.6}{58.0}$ \\
\hline Total & $\frac{33.9}{16.4}$ & $\frac{121.6}{72.1}$ & $\frac{203.0}{79.6}$ & $\frac{335.1}{81.4}$ & $\frac{532.7}{108.0}$ & $\frac{501.4}{155.9}$ \\
\hline
\end{tabular}

*The bottom figures represent the carotenoid content of DMSO-treated fruits; the top figures are for the control.

$+\beta-Z$-acarotene was observed but was lost on rechromatography. 
DMSO treatments. The $\beta$-zeacarotene concentrations were at the level of detectability. The $\gamma$-carotene content was consistently lower in DMSOtreated Stage 3 fruits than in the corresponding control fruits.

The Tycopene content of fruits harvested at Stage 2 (Table 2) reached its maximum level on the ninth day of ripening. The maximum levels of $\beta$-zeacarotene and $\gamma$-carotene were attained on the eight and ninth day, respectively. Phytoene, phytofluene and $\beta$-carotene were still accumulating at the end of the sampling period (11 days).

The formation of phytoene, phytofluene and lycopene. was greatly inhibited by treatment of Stage 2 fruits with DMSO. In addition, the levels of $\beta$-zeacarotene and $\gamma$-carotene dropped markedly in DMSO-treated fruits. The $\beta$-carotene content was also reduced but the reduction was not as severe as that of the other carotenes.

Analysis of the carotenoid distribution in the high-beta tomato (Table 3) shows that the fruit contained not only more $\gamma$ - and $\beta$-carotenes than the normal red (low-beta) tomato line but also more $\beta$-zeacarotene. Treatment with DMSO resulted in the reduction of the synthesis of both the acyclic and cyclic carotenoids in the high-beta fruit. Tomes ${ }^{15}$ and Tomes et al. ${ }^{20}$ reported previously that the high-beta tomato contains more $\gamma$ - and $\beta$-carotenes than the normal red parent. $\beta$-Zeacarotene was not detected by these authors.

These results show that it is possible to partly inhibit the formation of $\beta$-carotene in the "Tutescent" tomato if the detached fruits were exposed to DMSO prior to the appearance of the yellow pigmentation. The 
Table I. 2. Effect of DMSO on carotenoid synthesis in ripening Stage 2 fruits of the "lutescent". tomato.*

$\mu \mathrm{g} / \mathrm{g}$ dry weight

\section{Days}

\begin{tabular}{cccccccccc} 
& 0 & 2 & 3 & 4 & 5 & 6 & 8 & 9 & 11 \\
\hline Phytoene & $\frac{0.2}{0.2}$ & $\frac{0.6}{0.1}$ & $\frac{4.6}{0.1}$ & $\frac{12.3}{0.7}$ & $\frac{17.3}{0.7}$ & $\frac{22.7}{1.1}$ & $\frac{51.6}{1.0}$ & $\frac{69.2}{4.1}$ & $\frac{97.5}{7.4}$
\end{tabular}

Phytofluene

$\frac{0}{0} \frac{\text { Trace }}{0} \quad \frac{1.9}{0} \quad \frac{3.7}{\text { Trace }} \frac{14.8}{0.4} \quad \frac{19.9}{0.6} \quad \frac{41.0}{1.1} \quad \frac{44.4}{2.3} \quad \frac{56.1}{6.5}$

Lycopere

$\frac{0}{0} \quad \frac{0.7}{0.1} \quad \frac{16.6}{0.4} \quad \frac{83.1}{1.0} \frac{156.1}{0.8} \frac{263.0}{1.1} \frac{447.5}{6.3} \frac{702.6}{22.6} \frac{671.8}{92.2}$

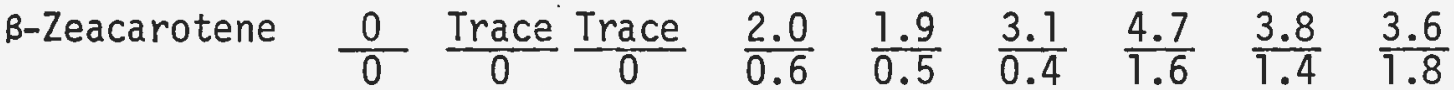

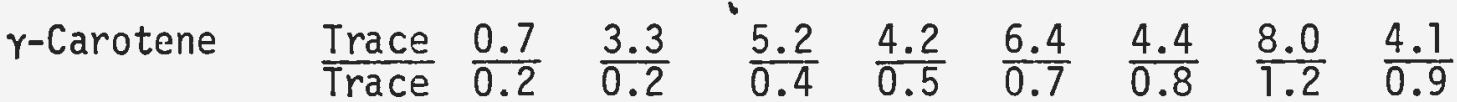
$\beta$-Carotene $\begin{array}{lllllllll}\frac{9.2}{10.4} & \frac{39.7}{24.6} & \frac{53.2}{33.5} & \frac{76.2}{37.7} & \frac{86.0}{46.6} & \frac{67.6}{49.5} & \frac{89.1}{87.7} & \frac{107.6}{107.1} & \frac{272.5}{127.4}\end{array}$

Tota 1

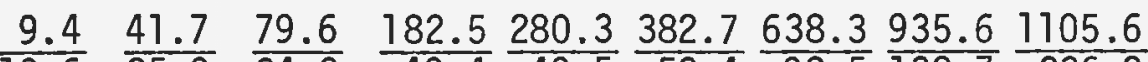
$\frac{9.4}{10.6} \quad \frac{41.7}{25.0} \quad \frac{79.6}{34.2} \quad \frac{182.5}{40.4} \frac{280.3}{49.5} \frac{382.7}{53.4} \frac{638.3}{98.5} \frac{935.6}{138.7} \frac{1105.6}{235.2}$

*The bottom figures represent carotenoid content of DMSO-treated fruits; the top figures are for the control. 
Table I. 3. Effect of DMSO on the biosynthesis of carotenoids in the high-beta tomato fruit.*

\begin{tabular}{|c|c|c|c|c|c|}
\hline \multirow[t]{2}{*}{ POLYENE } & \multicolumn{5}{|c|}{ 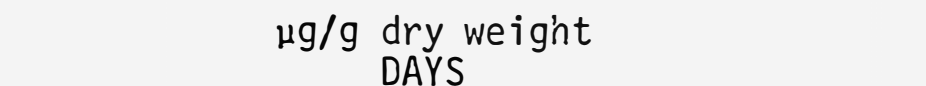 } \\
\hline & 0 & 6 & 8 & 12 & $12 * *$ \\
\hline Phytoene & $\begin{array}{l}0 \\
0\end{array}$ & $\frac{19.1}{3.1}$ & $\frac{17.1}{10.7}$ & $\frac{45.9}{21.4}$ & $\frac{22.9}{7.5}$ \\
\hline Phytofluene & $\frac{0}{0}$ & $\frac{10.3}{1.6}$ & $\frac{19.3}{7.5}$ & $\frac{25.4}{10.8}$ & $\frac{45.0}{4.4}$ \\
\hline Lycopene & $--\star \star \star \star$ & 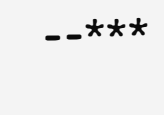 & 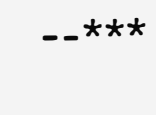 & 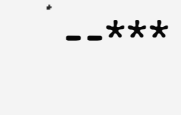 & $\frac{526.1}{172.7}$ \\
\hline B-Zeacarotene & $\frac{0.5}{1.4}$ & $\frac{2.0}{0.6}$ & $\frac{6.4}{2.5}$ & $\frac{7.8}{1.4}$ & $\frac{1.4}{1.2}$ \\
\hline$\gamma$-Carotene & $\frac{0}{0}$ & ${ }^{\circ} \frac{8.6}{0.5}$ & $\frac{10.5}{2.9}$ & $-\frac{11.8}{2.9}$ & $\frac{6.8}{5.4}$ \\
\hline B-Carotene & $\frac{26.3}{20.2}$ & $\frac{360.1}{152.1}$ & $\frac{549.6}{337.9}$ & $\frac{1074.7}{335.7}$ & $\frac{61.1 * * \dot{x *}}{61.3}$ \\
\hline TOTAL & $\frac{26.8}{20.7}$ & $\frac{400.1}{157.9}$ & $\frac{602.9}{351.5}$ & $\frac{1165.6}{372.2}$ & $\frac{663.3}{252.5}$ \\
\hline
\end{tabular}

*The bottom figures represent carotenoid content of DMSO-treated fruit; the top figures are for the control.

**Data from Raymundo et al. on DMSO treatments on low-beta "Summer. Sunrisa" tomato sträin added for comparison.

$* * *$ Lycopene was not detected. The two reddish bands above $\gamma$-carotene in the (MgO) column were not lycopene as judged from their absorption spectra.

$\star * * *$ The values represent total of the $\beta$-carotene and ' $\alpha$-carotene' fractions. The latter fraction has been shown to be an isomer of B-carotene. 
inhibition of $\beta$-carotene was not as extensive as the inhibition of 1ycopene and the other acyclic carotenes. These results are consistent with the proposal that two caroterogeric sites exist in the tomato fruit and that the formation of carotenes in a site once formed is not as susceptible to inhibition as in a developing site.

Thus, the system leading to $\beta$-carotene in the tomato fruit would seem to be formed at an earlier stage of maturity and is not as susceptible to inhibition as that system leading to lycopene. Dimethyl sulfoxide would appear to be involved in inhibiting the formation of the enzymatic system rather than inhibiting an existing system.

The results with the high-beta tomato would lead us to the conclusion expressed by Tomes ${ }^{15}$ that there are two kinds of $\beta$-carotene in the tomato fruit. Our results are interpreted to show that the additional B-carotene is formed through a system developed at a later maturity and thus is susceptible to DMSO inhibition. In the "Summer Sunrise" tomato at approximately the same maturity as the high-beta tomato, the lycopene and not the $\beta$-carotene synthesis was inhibited by DMSO.

It is not possible from the DMSO data to exclude lycopene as a precursor of B-carotene. However, it would seem unlikely from these studies that lycopene is the major precursor of $\beta$-carotene. In the three tomato Tines studied, $\beta$-zeacarotene and $\gamma$-carotene were inhibited to about the same extent. The finding of an increased level of $\beta$-zeacarotene in the high-beta tomato induced by the introduction of the ${ }_{B B}$, ${ }_{B}{ }_{B} \underline{m}_{B}$ genes would be consistent with the direct involvement of B-zeacarotene in the formation of $\gamma$ - and $\beta$-carotenes. 
Our conclusions are at variance with those reported by Kushwaha et al. ${ }^{13}$ who showed that the label from lycopene-15,15 ${ }^{3} \mathrm{H}$ is incorporated into $\gamma_{-}, \beta_{-}, \delta-, \alpha-$ and neo- $\beta$-carotenes by spinach leaf chloroplasts and by soluble plastid extracts of the high-beta and high-delta tomato selections. Decker and Uehleke ${ }^{11}$ showed that homogenates of the parenchymatous tissue of the tomato fruit could convert ${ }^{14} \mathrm{C}$-1ycopene to ${ }^{14} \mathrm{C}$ - $\beta$-carotene. More recently, $\mathrm{Hill}$ and Rogers ${ }^{14}$ obtained a similar conversion with disrupted bean chloroplasts and disrupted tomato fruit plastids. Decker and Uehleke ${ }^{11}$ also reported that the reaction lycopene $\rightarrow \beta$-carotene was reversible.

It would seem that the conversion of lycopene to the cyclic carotenes in various plant tissue preparations has been well established. It would seem equally clear from the data on DMSO, irradiation and ripening temperature experiments that lycopene cannot be an obligate intermediate in the biosynthesis of $\beta$-carotene in the tomato fruit. Two possible conclusions could be drawn from the lycopene conversion studies that would be consistent with the data presented:

(1) If the neurosporene $\rightarrow$ lycopene reaction were also reversible, the synthesis of 8 -carotene could have occurred through neurosporene and $\beta$-zeacarotene. The isolation of $\beta$-zeacarotene was not reported in any of the studies on the conversion of lycopene to the cyclic carotenes.

(2) It is also possible that the cyclization enzymes require only a completed chromophore on the end to be closed and are not specific for the presence or absence of a double bond at the $7^{\prime}, 8^{\prime}$ position. Thus 
lycopene could cyclize to $\gamma$-carotene and $\beta$-carotene; neurosporene would cyclize to $\beta$-zeacarotene. $\zeta$-Carotene and $\beta$-zeacarotene would not be suitable substrates for these enzymes. It would follow from this hypothesis that the ring-closure enzymes are not formed in the pathway leading to lycopene. However, if lycopene were added back to a plant tissue preparation, it might then be converted to $\gamma$-carotene and $\beta$-carotene.

Until the results of individual enzyme studies show otherwise, both schemes 6 and 7 of Williams et al ${ }^{21}$ would have to be considered in the interpretation of the data on the in vitro transformation of lycopene to other carotenes.

An analysis of the results of genetic studies by several workers ${ }^{7-9}$, $20,22,23$ on the inheritance of the ${ }^{+}{ }^{+} / B, \underline{m o}_{B}^{+} /{ }_{-} O_{B}$ genes (Table 4 ) appears to provide additional evidence for the existence of separate routes for lycopene and $\beta$-carotene in the tomato fruit. The rationale behind the suggested participation of Tycopene in the synthesis of $\beta$-carotene was that since the total carotenoid content remained unchanged in the presence of the $\underline{B}$ allele in the high-beta genetic line, the additional B-carotene must have been derived from 1ycopene. ${ }^{7,10}$ It might be assumed from this explanation that the $\underline{B}$ allele causes a shift in the equilibrium lycopene $\rightarrow \gamma$-carotene $\rightarrow \beta$-carutene towards $\beta$-carotene.

21 R.J.H. Williams, G. Britton and T. W. Goodwin, Biochem. J. 105, 99 (1967). 22 M. L. Tomes, F. W. Quackenbush, O. E. Nelson, Jr. and B. North, Genetics $23 \frac{38}{\mathrm{M}}, 117(1953)$.

$23 \frac{38}{M}$. L. Tomes, F. W. Quackenbush and T. E. Karg1, Bot. Gaz. 119,250 (1958). 
Table I. 4. Genotypes of the low-beta (normal red), intermediate-bata, and high-beta tomato strains.

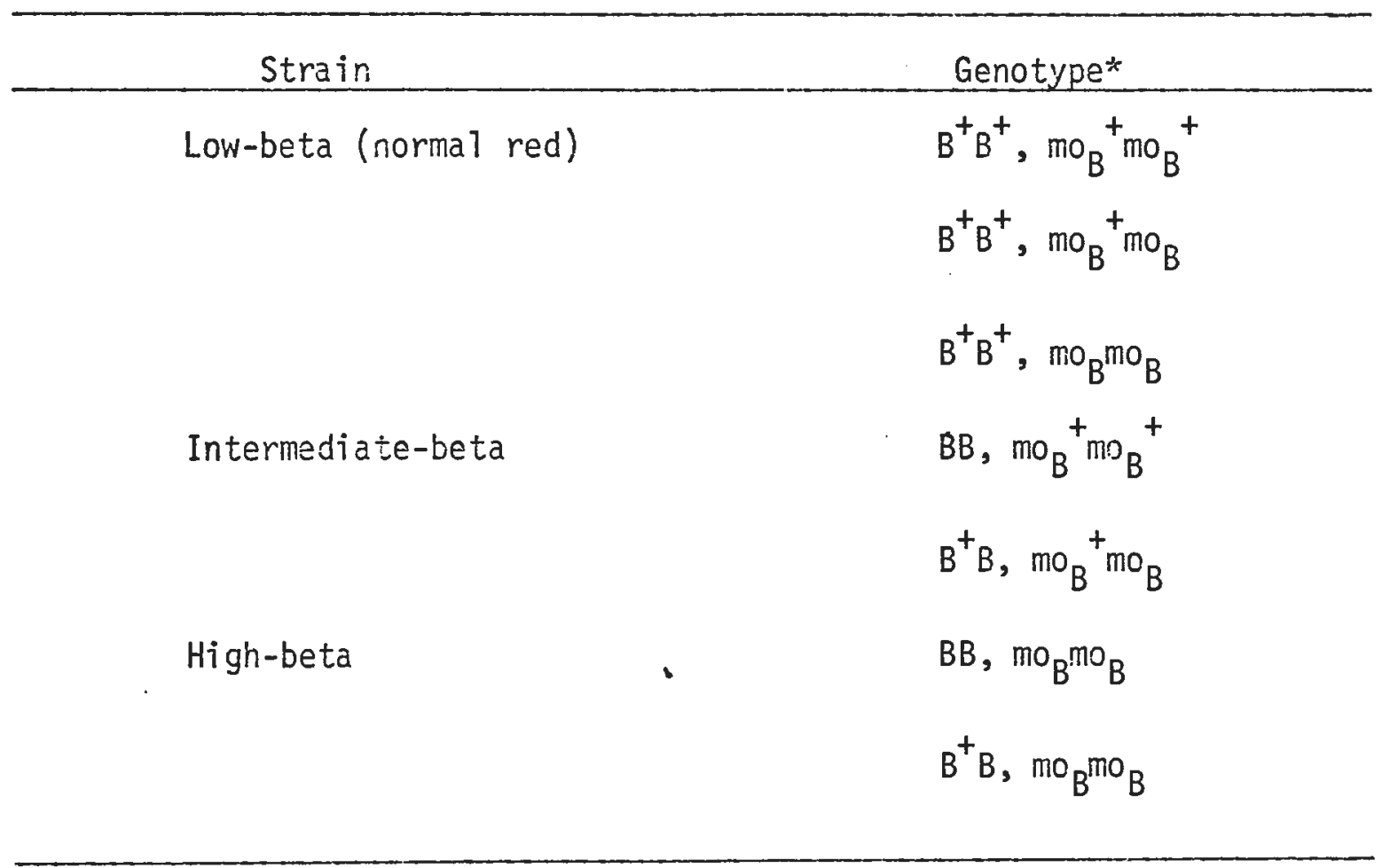

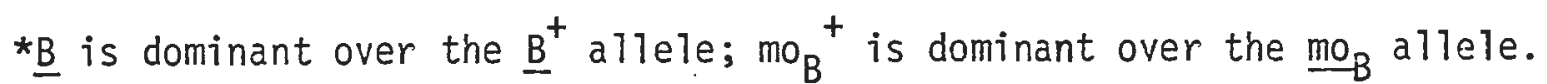


However, Tomes ${ }^{15}$ and Tomes et al. ${ }^{16}$ reported that part of the $\beta$-carotene in the high-beta tomato, unlike that in the normal red line, can be inhibited by ripening at high temperature. Therefore, the origin of the additional $\beta$-carotene in the high-beta must have been different from that of the normal red tomato.

The inhibitory effect of the $\mathrm{B}^{+} / \mathrm{B}, \mathrm{mo}_{B}{ }^{+} \mathrm{mo}_{B}$ genes on $1 \mathrm{y}$ copene formation may also be satisfactorily explained if one assumes that these genes control the balance between lycopene and $\beta$-carotene syntheses. In the presence of both dominant alleles $\underline{B}$ and $\underline{\mathrm{mo}}_{B}^{+}$, i.e. in the intermediate-beta line, both lycopene and $\beta$-carotene are synthesized in approximately equal amounts. ${ }^{15} \beta$-Carotene is produced only in large quantities, as in the high-beta line, when the interaction between the dominant $\underline{B}$ and the recessive $\underline{m O}_{B}$ alleles is expressed. Presumably, their products are required to produce an active repressor of the 1ycopene route, or alternatively, an effector substance for the $\beta$-carotene route. Finally, in the low-beta line, the $\beta$-carotene route is inoperative because the dominant $\underline{B}$ allele is absent.

The inhibition of $\beta$-zeacarotene and $\gamma$ - and $\beta$-carotene syntheses in mature green, high-beta tomato fruit (Table 3 ) by treatment with DMSO supports this interpretation. It is the synthesis of the additional levels of these carotenes induced by the presence of the $\underline{B}$ and $\underline{m o}_{B}$ alleles that is blocked by DMSO. In the high-beta tomato, therefore, there exist two separate pathways for $\beta$-carotene. One pathway is not sensitive to DMSO applied at the mature green stage. This is the "carry-over" path- 
way from the immature fruit. The second pathway, the "inducible" pathway, is the one that is selectively inhibited by DMSO. In the high-beta tomato fruit, the inducible pathway consists primarily of the $\beta$-carotene route; in the low-beta (normal red) fruit, it consists largely of the 1ycopene route.

The inducible pathway is presumably repressed in the immature tomato fruit. Derepression possibly occurs prior to the appearance of the first visible coloration on the green fruit. 


\section{EXPERIMENTAL}

Solvents and chromatographic adsorbents. The solvents and chromatographic adsorbents used were prepared as described previously. ${ }^{19}$

Fruits. The fruits of the "lutescent" and the high-beta tomato genetic lines were harvested from field-grown plants. Seeds of the highbeta tomato were generously provided by Dr. M. L. Tomes, Purdue University, Lafayette, Indiana, U.S.A.

Treatment with DMSO. The fruits were immersed in a 10\% solution of

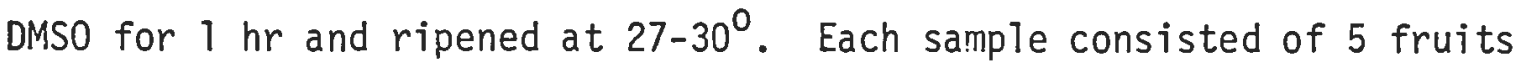
for the "lutescent" and 3 fruits for the high-beta line. The fruits were frozen at $-17^{\circ}$ and held in the freezer until analyzed.

Pigment extraction and chromatography. The extraction and purification procedures reported previous $1 y^{19}$ were modified as follows: The extract was washed free of acetone and then saponified with $200 \mathrm{ml}$ of $15 \%$ methanolic $\mathrm{KOH}$ on a steam table for 15-20 min. Saponification was carried out in the dark under a continuous stream of nitrogen gas. The pigments were transferred to light petroleum ether (P.E.) by the usual procedure $^{19}$ and washed free of alkali.

The pigment extract was diried over $\left(\mathrm{Na}_{2} \mathrm{SO}_{4}\right)$ prior to chromatography. The column was developed first with P.E. until the phytofluene band separated from the $\beta-\left(\right.$ or $\left.\alpha_{-}\right)$carotene band. Then $1 \%$ ether $-99 \%$ P.E. followed by $2 \%$ ether-P.E. were added to move the $\beta$-carotene band.

When the $\gamma$-carotene band separated from the 1ycopene band, $5 \%$ etherP.E. was added. $\beta$-Zeacarotene separated from $\gamma$-carotene upon the addi- 
tion of $2 \%$ acetone-P.E. Addition of $5 \%$ acetore-P.E. further resolved the various bands. The column was extruded after phytofluene was eluted and the various bands were cut and eluted from the adsorbent with acetone or ethanol in P.E.

The B-zeacarotene obtained from the (MgO) column did not need further purification. However, when it is contaminated with a substantial amount of a $\gamma$-carotene isomer, as indicated by the appearance of an additional peak at around $485 \mathrm{~nm}$, the pigment was rechromatographed on alumina (basic), activity grade III. B-Zeacarotene was eluted from the column with $1 \%$ ether-P.E.

Pigments more tightly adsorbed than lycopene were removed by passing the lycopene in P.E. washed free of ethanol through alumina III (neutral). The contaminants remained on the alumina. When $\gamma$-carotene appeared contaminated as judged from its spectrum, the pigment was rechromatographed on alumina III (neutral). The $\gamma$-carotene band was eluted from the colurin with P.E.

The fraction containing the phytoene collected from the (Mg0) column was purified by rechromatography on $15 \mathrm{~g}$ of alumina (neutral), activity grade I. Spectral grade pentane or hexane was used in the purification procedure. Five $\mathrm{ml}$ fractions were collected with a fraction collector. Seventy $\mathrm{ml}$ of the solvent were collected before $150 \mathrm{ml}$ of $1 \%$ ether in pentane or hexane were added to develop the column. This was followed by $150 \mathrm{ml}$ of $2 \%$ ether. Phytoene appeared between fractions 30 and 50 . 
Pigment identification. The various carotenoids were identified on the basis of their position on the (MgO) column and their absorption spectra. 25

Acknowledgements--This investigation was supported by National Science Foundation Grant GB 6213 and by the Public Health Service Research Grant No. 1 R01 NB 08516-01 of the National Institute of Neurological Diseases and Stroke.

25 B. H. Davies, In Chemistry and Biochemistry of Plant Pigments (Edited by

T. W. Goodwin), p. 489. Academic Press, New York (1965). 
PART II. THE EFFECT OF 2-(4-CHLOROPHENYLTHIO)-TRIETHYLAMINE HYDROCHLORIDE (CPTA) ON CAROTENE FORMATION IN PHYCOMYCES AND DETACHED TOMATO FRUIT 
THE EFFECT OF 2-(4-CHLOROPHENYLTHIO)-TRIETHYLAMINE HYDROCHLORIDE (CPTA) ON CAROTENE FORMATION IN PHYCOMYCES AND

\section{DETACHED TOMATO FRUIT}

T. H. Lee*, L. C. Raymundo, D. Rodriguez, K. L. Simpson and

C. 0 . Chichester

Department of Food and Resource Chemistry

University of Rhode Island

Kingston, Rhode Island 02881, U.S.A.

Recently Coggins, Henning \& Yokoyama (1970) reported that 2-(4-chlorophenylthio)-triethylamine hydrochloride (CPTA) causes the accumulation of lycopene in a wide spectrum of carotenogenic systems, such as fruits, vegetables, or moulds that either do not produce lycopene or produce it in minor amounts. Lycopene accumulation has also been reported by Howes \& Batra (1970), in Mycobacterium marinum treated with nicotine, and by Knypl (1969), in pumpkin cotyledons treated with Cycocel [(2-chloroethy1)trimethylammonium chloride].

In view of the wide response to CPTA and its suggested usefulness for studying carotene cyclization, it is of interest (i) to determine the changes in the other carotenes present, and ( $i i)$ to see whether CPTA can induce lycopene synthesis in mutants which accumulate large amounts of phytoene. The present paper reports the results of the analysis of the pigmentation pattern for CPTA-treated Phycomyces blakesleeanus and an albino mutant of this mould. The effect of CPTA on pigmentation in the fruit of the high-beta and ghost tomato mutants is also reported.

*Address: Department of Food Technology University of New South Wales P. 0. Box 1, Kensington, N.S.W. 2033 Australia 


\section{EXPERIMENTAL METHODS}

P. blakesleeanus NRRL 1554- was obtained from the Northern Utilization Research and Development Division, U.S.D.A., Peoria, I11., U.S.A.

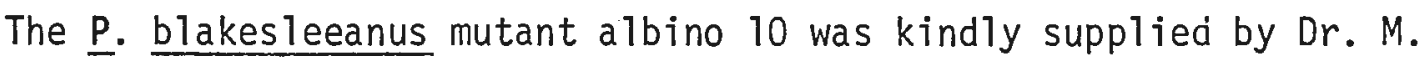
Delbruck of the California Institute of Technology, Pasadena, Calif., U.S.A. The tomato seeds were the generous gifts of Dr. M. L. Tomes of Purdue University, Lafayette, Indiana, U.S.A. (high-beta) and Dr. C. M. Rick of the University of California, Davis, Calif., U.S.A. (ghost).

The moulds were grown in a controlled environmental shaker (Psychrotherm, New Brunswick Scientific, New Brunswick, N. J., U.S.A.), Conditions were as follows: speed' of shaker, $150 \mathrm{rpm}$; temperature, $20^{\circ} \mathrm{C}$; and illumination, fluorescent lamps giving a light intensity of 3000 lux at the liquid surface. The high-beta and ghost plants were grown in the field and glasshouse, respectively; the fruits were harvested at the breaker stage of maturity and immediately treated.

CPTA at a concentration of $25 \mathrm{ppm}$ was added to the mould culture 26 hours after inoculation from a spore suspension (cf. Lee and Chichester, 1969). The moulds were cultured for an additional 3 days prior to harvest.

Tomato fruits were injected with either distilled water or CPTA solution (4300 ppm) and allowed to ripen at $25^{\circ}$ for 12 days. Fruits injected with distilled water exhibited no observable change in the pigmentation pattern. CPTA treated fruits, however, developed red areas 
around the point of injection. The red areas were dissected from each of the 12 treated high-beta fruit, combined and aralyzed. The yellow portions of the fruit served as the control. The ghost tomato had no red areas following injection of CPTA and thus the whole fruit (32 per treatment) was used for analysis.

The extraction, purification, identification, and estimation of the carotenoid pigments of moulds (Lee and Chichester, 1969; Simpson, Nakayama and Chichester, 1964) and in tomatoes (Raymundo, Griffiths and Simpson, 1967, 1970) have been previously described in detail. 


\section{RESULTS}

The results of the CPTA treatment of Phycomyces and the tomatoes are summarized in Table 1 . When $\underline{P}$. blakesleeanus was grown in the presence of 25 ppni of CPTA for 3 days the total carotencid content increased by about $1 / 3$. There was generally a slight increase in the acyclic carotenes with a large increase in the level of lycopene. $\beta$-Carotene was found to decrease, but CPTA caused a significant increase in the level of $\gamma$-carotene.

$\gamma$-Carotene was not detected in the untreated mould. The spores and the mycelia of the $R_{1}$ mutant of $\underline{P}$. blakesleeanus do contain a large amount of $\gamma$-carotene and Tycopene (Meissner and Delbruck, 1969; Lee et al., personal communication). Howes and Batra (1970) were not able to detect $\gamma$-carotene in untreated cells of $\underline{M}$. marinum.: However, $\gamma$-carotene could be isolated from cells treated with suboptimal amounts of nicotine which had resulted in a reduction of $\beta$-carotene. Increasing the concentration of CPTA up to $200 \mathrm{ppm}$ resulted in additional increases in the lycopene concentration. Higher concentrations of CPTA tended to be toxic. Coggins et al. (1970) reported similar stimulation of lycoperie synthesis in $\underline{P}$. blakesleeanus with 15 ppm CPTA. However, they did not report the changes in the other carotenes.

Coggins et al. (1970) reported also that they treated 4 strains of tomatoes that do not form lycopene and found that lycopene became the major pigment. We treated the high-beta tomato fruit with CPTA and also 
found a very large increase in lycopene. Analys is of the total carotene content showed that the increase in lycopene is accompanied by a general increase in the other acyclic carotenes. The cyclic carotenes, $\beta$-zeacarotene and $\gamma$-carotene, decreased slightly; however, there is a very large decrease in the level of $\beta$-carotene. The net effect of CPTA was to decrease the total carotene accumulation. These results are consistent with those of dimethylsulfoxide (DMSO) treatment of normal red, "lutescent" and high-beta tomato fruits, which led Raymundo et al. (1967, 1970) to propose that the main route of $\beta$-carotene synthesis is through $\beta$-zeacarotene rather than lycopene.

The results with the albino 10 mould are of particular interest since polyene synthesis genetically is blocked after phytoene. Total polyene synthesis was increased by CPTA as in the wild type mould, thus showing that the chemical was still able to stimulate the channelling of precursors to the phytoene level.

The effect of CPTA treatment on the ghost tomato was negligible. There was a very slight increase in lycopene and decrease in $\beta$-carotene with the total carotenoids nearly the same. The major polyene, phytoene, showed no change. Thus, in the albino 10 mould and ghost tomato where large amounts of the carotene precursor phytoene are already present, lycopene synthesis was not stimulated, suggesting that CPTA exerts its influence only in an already existing pathway and will not remove a block induced by genetic mutation. On the other hand, CPTA could act by 
channelling the precursors away from $\beta$-carotene to lycopene synthesis.

This is supported by the data on the high-beta tomato where both pathways are presumably operating (Raymurdo, Griffiths and Simpson, 1970), the $\underline{B B},{ }^{m o} B{ }_{B}{ }_{B}$ genes simply shifting the synthesis toward $\beta$-carotene formation.

Acknowledgements--We wish to thank Amchem Products, Inc., Ambler, Pa. 19002 for their generous gift of 2-(4-chlorophenyl thio)-triethylamine hydrochloride. The research was supported by U. S. Public Health Service Grants Am-11665 to C. 0. Chichester and NB-08516-01 to K. L. Simpson. The technical assistance of Mrs. J. B. Leathers is acknowledged. This paper is contribution No. 1393 of the University of Rhode Island Agricultural Experiment Station. 
Table II. 1. Carotenoid distribution in Phycomyces blakesleeanus and in detached tomato fruits treated with CPTA.*

\begin{tabular}{|c|c|c|c|c|}
\hline Polyene & \multicolumn{2}{|c|}{ Phycomyces blakesleeanus } & \multicolumn{2}{|c|}{ Tomato } \\
\hline Phytoene & $\frac{65}{85}$ & $\frac{977}{1298}$ & $\frac{107}{162}$ & $\frac{1168}{1769}$ \\
\hline Phytofluene & $\frac{11}{35}$ & $\frac{\text { Tracet }}{-}$ & $\frac{46}{73}$ & $\frac{122}{123}$ \\
\hline$\zeta$-Carotene & $\frac{16}{21}=$ & & $\frac{8}{16}$ & $\frac{18}{28}$ \\
\hline Neurosporene & $\frac{6}{4}$ & & - & - \\
\hline Lycopene & $\frac{2}{102}$ & 6 & $\frac{40}{672}$ & $\frac{36}{47}$ \\
\hline$\beta$-Zeacarotene & $\frac{-}{\text { Trace }}$ & & $\frac{4}{2}$ & - \\
\hline$\gamma$-Carotene & $\frac{-}{58}$ & & $\frac{47}{35}$ & - \\
\hline$\beta$-Carotene & $\frac{393}{361}$ & & $\frac{1398}{360}$ & $\frac{14}{5}$ \\
\hline Total & $\frac{498}{666}$ & $\frac{977}{1298}$ & $\frac{1650}{1291}$ & $\frac{1358}{1372}$ \\
\hline
\end{tabular}

*The top figure in each category represents the carotenoid content (in $\mathrm{ug} / \mathrm{g}$ dry weight) of the control and the bottom figure represents the value for the corresponding treated material. Each figure is the average of duplicate determinations.

+Detected on the column when viewed with UV light. 


\section{REFERENCES}

Coggins, Jr., C. W., Henning, G. L. \& Yokoyama, H. (1970). Science 168. 1589.

Goodwin, T. W. (1965). In Chemistry and Biochemistry of Plant Pigments, p. 143. Ed. by Goodwin, T. W. , New York: Academic Press, Inc.

Howes, C. D. \& Batra, P. P. (1970). Biochim. Biophys. Acta 222, 174.

Knyp1, J. S. (1969). Naturwissenschaften 56, 572 .

Lee, T.-C. \& Chichester, C. 0. (1969). Phytochem. ㅇ, 603.

Meissner, G. \& Delbruck, M. (1968). Plant Physiol: 43, 1279.

Raymundo, L. C., Griffiths, A. E. \& Simpson, K. L. (1967). Phytochem. ㅁ, 1527.

Raymundo, L. C., Griffiths, A. E. \& Simpson, K. L. (1970). Phytochem. 9, 1239.

Simpson, K. 1., Nakayama, T. 0. M. \& Chichester, C. 0. (1964). ‥ Bact. $\underline{88}$, 1688. 
PART III. THE ISOLATION OF A POLY- $\underline{\underline{C I S}} \zeta$-CAROTENE FROM THE TANGERINE TOMATO 
THE ISOLATION OF A POLY-CIS $\zeta$-CAROTENE FROM

THE TANGERINE TOMATO ${ }^{1}$

Leoncio C. Raymundo and Kenneth L. Simpson

Department of Food and Resource Chemistry University of Rhode Island

Kingston, Rhode Is land 02881 U.S.A.

Abstract--A contaminant of the $\beta$-carotene fraction of tangerine tomato fruit extract was isolated and identified as a poly-cis isomer of $\zeta$-carotene. The ripening fruit contains $0.8 \mathrm{ug} / \mathrm{g}$ dry weight of the pigment. The possible role of poly-cis $\zeta$-carotene in the biosynthesis of poly-cis carotenes is discussed.

\section{INTRODUCTION}

Tangerine tomato fruits contain as the characteristic pigments the poly-cis carotenes proneurosporene and prolycopene ${ }^{2}$ and smaller amounts of cis isomers of phytofluene and $\zeta$-carotene. ${ }^{3}$ Compared with ordinary tomatoes, the tangerine fruits have reduced levels of all-trans lycopene and $\beta$-carotene, but greatiy increased amounts of the more saturated carotene precursors phytoene, phytofluene and $\zeta$-carotene.

${ }^{1}$ Contribution Number 1383 of the Rhode Island Agricultural Experiment Station.

2A. L. LeRosen and L. Zechmeister, J. Amer. Chem. Soc. 64, 1075 (1942).

3. J. H. Williams, G. Britton, J. M. Charlton and T. W. Goodwin, Biochem. J. 104,767 (1967). 
The phytoene and phytofluene levels in the ripe tangerine tomato are surpassed only by the levels of these polyenes in the ghost tomato. ${ }^{4,5}$ The all-trans $\zeta$-carotene content which has been reported to amount to $414.4 \mathrm{ug} / \mathrm{g}$ dry weight ${ }^{3}$ is the highest concentration of this pigment found in tomato fruits. ${ }^{6,7}$ The $\beta$-carotene content, on the other hand, is more typical of the values reported for green tomatoes. 4

In the present paper we report the identification of a poly-cis isomer of $\zeta$-carotene from extracts of tangerine tomatoes.

\section{RESULTS AND DISCUSSION}

A contaminant of the $\beta$-carotene fraction eluted from the $\mathrm{MgO}$ : Hyflo Super Cel column was isolated during the purification of $\beta$-carotene by TLC on silica gel $\mathrm{F}$ plates. The adsorption maxima of the yellow pigment were different from any of the carotenes whose fundamental band falls between the 370 and $420 \mathrm{~nm}$ region of the spectrum.

${ }^{4}$ G. Mackinney, C. M. Rick and J. A. Jenkins, Proc. Nat. Acad. Sci. U.S. $42,404(1956)$.

${ }^{5}$ M. L. Tomes, Bot. Gaz. 124, 180 (1963).

6. W. Porter and F. P. Zscheile, Arch. Biochem. 10, 537 (1946).

7J. W. Porter and R. E. Lincoln, Arch. Biochem. 27, 390 (1950). 
The pigment exhibited $\lambda_{\max }$ at 414,390 and $369 \mathrm{~nm}$ which shifted to 422, 397 and $377 \mathrm{~nm}$ on the addition of catalytic amounts of iodine (Fig. 1). The extinction of the fundamental region also increased concomitant with the bathochromic shift. The absorption of the iodine catalyzed equilibrium mixture is identical to the spectral curve of the stereoisomers obtained upon iodine catalysis of the all-trans $\zeta$-carotene.

A strong bathochromic shift and an increase in the extinction at the fundamental region on iodine catalysis are characteristic properties exhibited by al1 poly-cis carotenoids. ${ }^{8}$ These data are consistent with the conclusion that the isolate is a poly-cis isomer of $\zeta$-carotene.

In the ripening fruit the poly-cis $\zeta$-carotene was found at a concentration of $0.8 \mathrm{ug} / \mathrm{g}$ dry weight which is about $0.4 \%$ of the total $\zeta$-carotene content of $189.2 \mathrm{ug} / \mathrm{g}$ dry weight.

A comparison of the absorption maxima of the poly-cis $\zeta$-carotene with the spectrum of some synthetic and natural isomers of $\zeta$-carotene is given in Table 1.

${ }^{8}$ L. Zechmeister, cis-trans Isomeric Carotenoids, Vitamins A and Arylpolyenes, Springer-Verlag: Vienna (1963). 
Fig. II 1.1. Specific extinction curves of poly-cis $\zeta$-carotene, in petroleum ether: (a) fresh solution; (b) mixture of stereoisomers after catalys is by iodine; and (c) mixture of stereoisomers after catalysis of all-trans $\zeta$-carotene by iodine. 


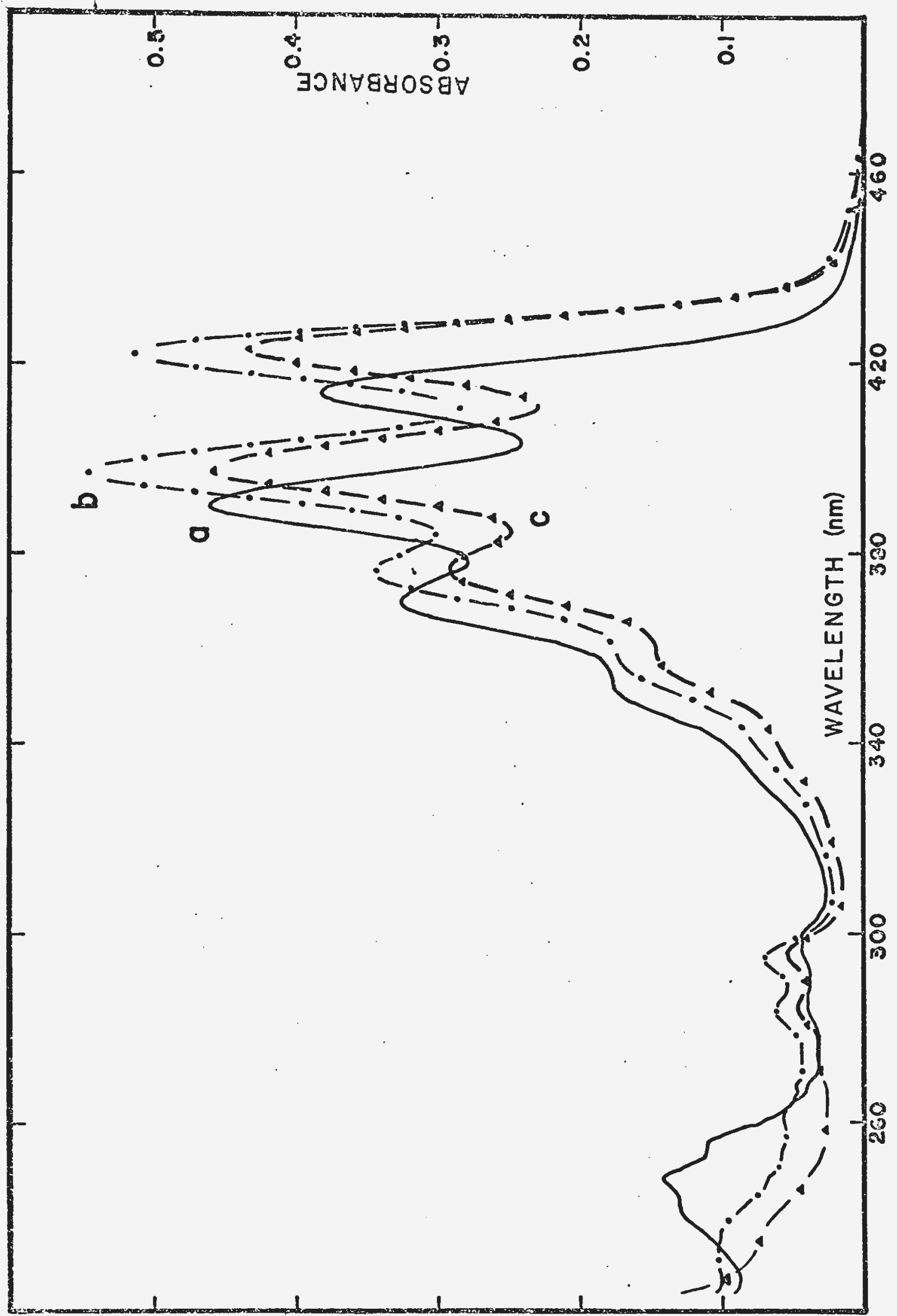


Table III. 1. $\lambda_{\max }$ of the poly-cis $\zeta$-Carotene and Some Natural and Synthetic Isomers

\begin{tabular}{|c|c|c|c|c|c|c|c|}
\hline Isomer & Source & & & $\max$, & $\mathrm{nm}$ & & Reference \\
\hline a 11 -trans $\zeta$-Carotene & Carrot oil & 425 & 400 & 378 & (361) & & 9 \\
\hline a)17-trans $\zeta$-Carotene & Synthetic & 425 & 401 & 380 & & & 10 \\
\hline unsym. $\zeta$-Carotene & Synthetic & 420 & 395 & 375 & (356) & & 9,10 \\
\hline $\begin{array}{c}\text { unsym. } 5 \text {-Carotene } \\
(7,8,11,12 \text {-Tetra- } \\
\text { hydrolycopene })\end{array}$ & $\begin{array}{l}\text { Rhodospiril- } \\
\text { lum rubrum }\end{array}$ & 478.5 & 394.5 & 374 & (354) & & 11 \\
\hline "neo A" $\zeta$-Carotene & Carrot oil & 419 & 396 & 375 & (357) & 296 & 2859 \\
\hline cis-15- $\zeta$-Carotene & Synthetic & 422 & 398 & 378 & (359) & 296 & 2869,10 \\
\hline cis $\zeta$-Carotene & $\begin{array}{c}\text { Tangerine } \\
\text { toma to }\end{array}$ & 423 & 398 & 378 & & & 3 \\
\hline poly-cis $\zeta$-Carotene & $\begin{array}{c}\text { Tangerine } \\
\text { toma to }\end{array}$ & 414 & 390 & 369 & (352) & 296 & 285 \\
\hline
\end{tabular}

9. B. Davis, L. M. Jackman, P. T. Siddons and B. C. L. Weedon, J. Chem. Soc. (C), 2154 (1966).

10J. B. Davis, L. M. Jackman, P. T. Siddons and B. C. L. Weedon, Proc. Chem. Soc., 261 (1961).

11 B. H. Davies, Biochem. J. 116, 93 (1970). 
The structure of poly-cis carotenoids has not been satisfactorily elucidated. Based on spectral studies of cis-trans carotenoids and related polyenes, Zechmeister ${ }^{8}$ suggested that prolycopene has a symmetrical structure with cis configuration at the central double bond and 4 other sterically unhindered double bonds. The unhindered positions are the methylated carbon-to-carbon double bonds in the carotenoid molecule. ${ }^{12}$ Introduction of hindered cis double bond $(-s)$ results in the loss of fine structure in the fundamental region. $8,13,14$

The absence of a strong cis-peak in the near ultraviolet region of the poly-cis $\zeta$-carotene spectrum suggests that the molecule does not have a bent shape. The central mono-cis isomer, e.g. central mono-cis isomers of $\beta$-carotene and lycopene, has the strongest cis-peak because of its bent shape; conversely, the spectral curve of the all-trans isomer has a relatively flat, although slightly elevated cis-peak region. ${ }^{8}$

12L. Pauling, Fortschr. Chem. organ. Naturstoffe 3, 203 (1939).

${ }^{13}$ C. H. Eugster, C. F. Garbers and P. Karrer, Helv. Chim. Acta 36, 1378 (1953).

${ }^{14} 0$. von Isler, L. H. Chopard-dit-Jean, M. Montavon, R. Ruegg and P. Zeller, Helv. Chim. Acta 40, 1256 (1957). 
In view of our present isolation of a poly-cis $\zeta$-carotene, we suggest that the proposed pathway of Porter and Anderson ${ }^{15}$ be modified to include this new compound as an intermediate. The poly-cis 5 -carotene could be formed from the all-trans $\zeta$-carotene. The existence of three poly-cis polyenes would lead one to suggest that poly-cis phytoene and phytofluene might also be formed in the system (Fig. 2). These compounds, however, have not been reported. If they were formed their poly-cis nature would be difficult to detect since most of the unhindered $\underline{c i s}$ positions would be out of conjugation. Such a parallel pathway would be similar to one proposed by Malhotra, Britton and Goodwin ${ }^{17}$ for the biosynthesis of 1,2-dihydro carotenes from 1,2-dihydro phytoene in Rhodopseudomonas viridis.

15J. W. Porter and D. G. Anderson, Arch. Biochem. Biophys. 97, 520 (1962). 16 J. W. Porter and D. G. Anderson, Ann. Rev. Plant Physiol. 18, 197 (1967). 17 H. C. Malhotra, G. Britton and T. W. Goodwin, Internat. Z. Vit. Forschung $40,315(1970)$. 
Fig. III,2. Possible pathways leading to the formation of prolycopene. 


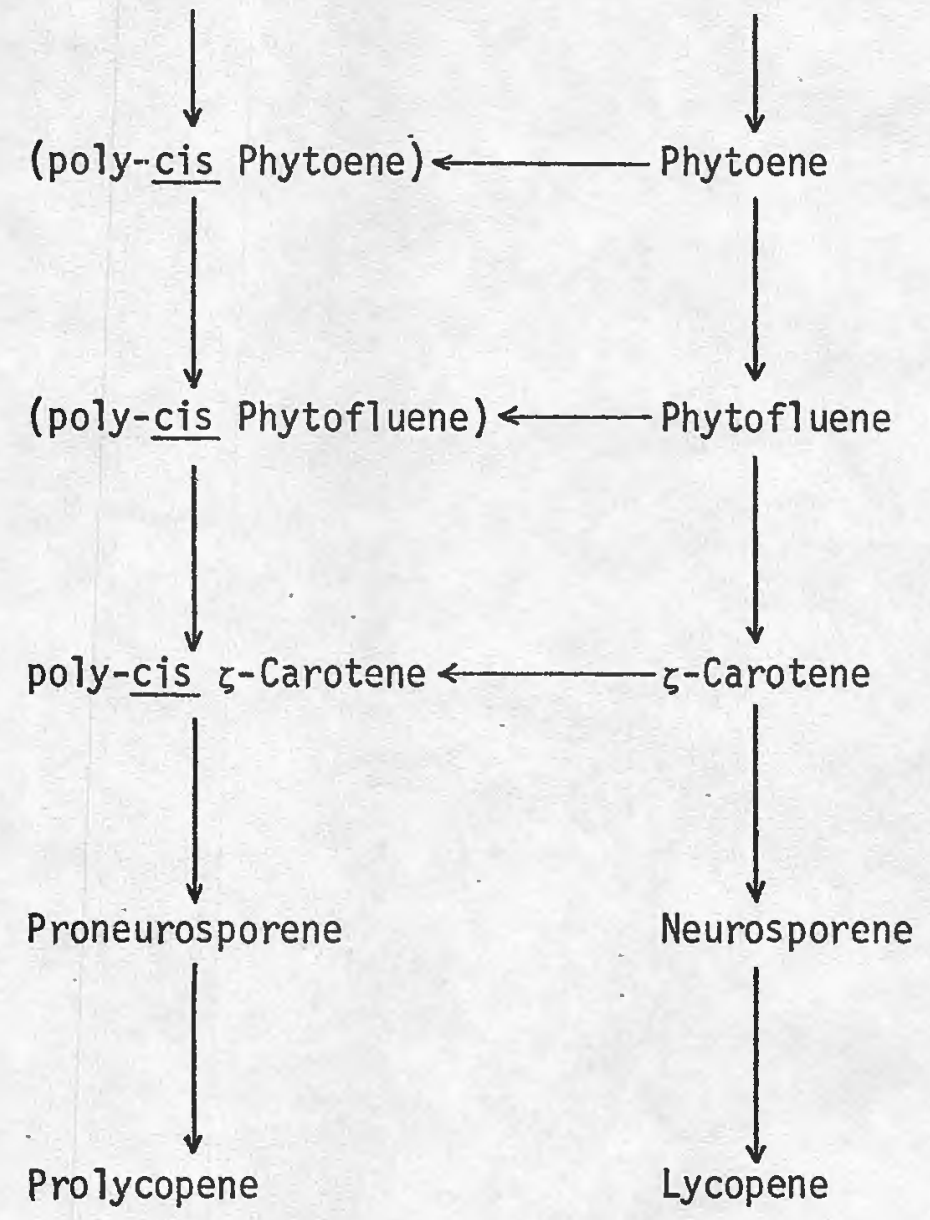




\section{EXPERIMENTAL}

Materials--Field ripened Tangerine tomato fruits were used in this study. The seeds were a gift from Dr. M. L. Tomes of the Department of Botany and Plant Pathology, Purdue University, Lafayette, Indiana, U.S.A.

Pigment Extraction and Purification--Thirty-gram aliquots of the fruit were extracted with acetone-petroleum ether (P.E., b.p. 30-50 ) in a Waring Blendor under a continuous stream of nitrogen gas. The extract was washed immediately with water to remove the acetone. The extract was either chromatographed after drying $\left(\mathrm{Na}_{2} \mathrm{SO}_{4}\right)$ without prior saponification or saponified with $10 \% \mathrm{KOH}$ in methanol $(w / v)$. Saponification was accomplished by evaporating the P.E. in a flash evaporator to transfer the pigment extract into the methanolic solution. The extract was transferred to P.E. after $15 \mathrm{~min}$. following the usual procedure, ${ }^{18}$ dried $\left(\mathrm{Na}_{2} \mathrm{SO}_{4}\right)$ and chromatographed on a $22 \times 360 \mathrm{~mm}$ column of MgO:Hyflo Super Ce1 (1:2,w/w). The chromatogram was developed with 2,5 and finally $10 \%$ acetone in P.E. The column plug was extruded and the zone below the cis $\zeta$-carotene band was cut together with the $\beta$-carotene band. The pigments were eluted from the adsorbent with acetone-P.E., evaporated to dryness and rechromatographed on a $12 \times 150$ column of alumina II.

18 L. C. Raymundo, A. E. Griffiths and K. L. Simpson, Phytochem. 6, 1527 (1967). 
The column was developed with increasing concentrations of diethyl ether in P.E. The poly-cis $\zeta$-carotene was eluted from the column together with the $\beta$-carotene band with $5 \%$ ether. The eluate was evaporated to dryness and purified by TLC on precoated silica gel $F_{254}$ plates with P.E. as developing solvent. The yellow band adsorbed below the $\beta$-carotene band is the poly-cis $\zeta$-carotene band. Alternatively, the eluate from the Mg0: Hyflo Super Cel column was first purified by TLC on precoated silica gel $F_{254}$ plates to remove the $\beta$-carotene. The poly-cis $\zeta$-carotene band was eluted from the adsorbent and rechromatographed on a short column of alumina II to remove a contaminating $\beta$-zeacarotene-like pigment.

Absorption Spectra--The absorption spectra of the carotenes were recorded from solutions in P.E. contained in a glass-covered quartz cell with a Cary 15 recording spectrophotometer. Quantitative estimation of the poly-cis $\zeta$-carotene was made from the equilibrium mixture of stereoisomers after the poly-cis pigment was subjected to iodine catalysis using the $E_{l \mathrm{~cm}}^{l \%}$ value of 2270 for the all-trans $\zeta$-carotene at $400 \mathrm{~nm} .{ }^{19}$ Acknowledgements--This investigation was supported by the Public Health Service Research Grant No. 1 R01/NB 08516-01 of the National Institute of Neurological Diseases and Stroke. The assistance of Dr. A. E. Griffiths is gratefully acknowledged.

19. H. Davies, In Chemistry and Biochemistry of Plant Pigments, (edited by T. W. Goodwin), p. 489, Academic Press: New York (1965). 
$\checkmark$

APPENDIX 


\section{IN RETROSPECT}

A. The Protective Function of Carotenoids Against Photosensitized Oxidation

Carotenoids are invariably the most widely distributed pigment in Nature (Goodwin, 1965a). They are present without exception in a11 photosynthetic tissues of prokaryotic and eukaryotic organisms. To explain the ubiquity of carotenoids, attempts have been made to define their function among carotenogenic organisms by correlating their presence to certain physiological and morphological responses (Burnett, 1965). So far, however, only their protective function against photosensitized oxidation has been thoroughly and unambiguously documented (Krinsky, 1968).

Griffiths, Sistrom, Cohen-Bazire and Stanier (1955) demonstrated the protective role of carotenoids in Rhodopseudomonas spheroides against photooxidation catalyzed by its own bacteriochlorophy11. Cel1s of a blue-green mutant devoid of colored carotenoids were killed when illuminated under aerobic condition but remained normal in the dark or at low light intensity, or when grown anaerobically in the presence of light. Similar observations have been made by Claes (1954) in Chlorella vulgaris in which mutants accumulating the more saturated carotenes, phytoene, phytofluene and 5 -carotene were killed when exposed to visible light in the presence of oxygen. Chance and Sager (1957) also reported the photodynamic killing of an analogous mutant of Chlamydomoras reinhardi.

Photooxidative destruction of chlorophyll in the absence of colored carotenoids has also been reported in higher plants (Koski and Smith, 
1951; Wallace and Schwarting, 1954; Smith, Durham and Wurster, 1959;

Anderson and Robertson, 1960, 1963; and Walles, 1967). Walles (1965, 1966) described the structural changes in plastids of dark-grown albina and xantha mutants of sunflower which lead to bleaching upon illumination. He concluded that carotenoids do not influence the synthesis and organization of the prolamellar body in the developing plastid.

Unlike the wild type, the xantha mutant accumulates xanthophylls but not $\beta$-carotene while the albina mutant does not synthesize colored carotenoids (Habermann, 1960). Xantha does not bleach as rapidly as the albina mutant on illumination, implying that the xanthophylls offer some degree of protection against photosensitized oxidation and that $\beta$-carotene is necessary to maintain the structural integrity of the plastids formed in the dark. The grana and the chlorophyll incorporated into the grana are unstable and rapidly destroyed by light in the absence of $\beta$-carotene (Walles, 1967).

Faludi-Daniel and Lang (1964) described two mutants of corn, one of which accumulates $\zeta$-carotene while the other accumulates lycopene. The chlorophyll formed by these mutants at low light intensities is destroyed on subsequent exposure to high light intensities. An analogous situation was observed in albescent corn mutant (Sander, Laber, Bell and Hamilton, 1968).

The protective function of carotenoids against lethal photosensitized oxidations by visible light has been reported in non-photosynthetic chromogenic bacteria (Mathews and Sistrom, 1959; Wright and Rilling, 1963; 
Mathews, 1964; : Kathews-Roth and Krinsky, 1970a,b,c) and in yeasts (Chichester and Maxwe11, 1969). The photodynamic effect of visible light in these organisms is catalyzed by other light-absorbing compounds. A comprehensive review of the subject was made by Krinsky (1968).

Krinsky $(1966,1968)$ suggested a scheme for the deactivation of the excited chlorophyll-oxygen complex. It involves epoxidation of zeaxanthin to antheraxanthin which is a non-enzymatic process; regeneration of zeaxanthin is catalyzed by antheraxanthin de-epoxidase. Yamamoto, Nakayama and Chichester (1962) observed that violaxanthin can be converted to zeaxanthin via antheraxanthin anaerobically in light by leaf segments from spinach and lima beans. They concluded that the conversion is enzymic because a mild heat treatment can reduce the reaction. Dworkin (1959) did not observe bleaching of chlorophyll in Rhodopseudomonas spheroides at $1^{0}$ although photokilling occurred, suggesting that part of the protective mechanism is enzymic. Carotenoids of pigmented Sarcina lutea offered lesser protection against photosensitization by toluidine blue in air at $4^{\circ}$ than at $34^{\circ}$ (Mathews, 1964).

Yamamoto and Chichester (1965) also reported the incorporation of $\mathrm{O}_{2}$ into antheraxanthin in the dark following exposure of bean leaves to intense light.

The mechanism that has been suggested whereby carotenoids are able to quench the excited state of chlorophyll is the photoinduced isomerization of carotenoids. Rau and Zehender (1959) found that the fungus 
Fusarium aquaeductum accumulated poly-cis lycopene II when aerated in 1ight. By x-rày irradiation, Claes (1954, 1956, 1957) obtained a Chlorella mutant which produces prolycopene and proneurosporene when grown in the dark. On subsequent illumination of the dark-grown culture with blue light, the poly-cis isomers disappeared concomittant with the formation of a 11-trans 1ycopene and al1-trans neurosporene. According to Claes and Nakayama (1959) cis $\rightarrow$ trans isomerization can also occur in red light both in vivo and in vitro provided that chlorophyll is present. Apparent7y, the chlorophyll acts as the photosensitizer. The photoinduced isomerization was inhibited by oxygen. Schroeder (1942) similarly reported the presence of prolycopene and pro-r-carotene in the petals of the monkey flower, Mimulus longiflorus, at low light intensity; at high light intensity, only the corresponding all-trans isomers are produced.

Reviews of the mechanisms of sensitized photooxidation in biological systems have been published recently (Spikes and Straight, 1967; Foote, 1968).

The herbicidal property of 3-amino-1,2,3-triazoie (Amitrole), 3,4dichlorobenzyl methylcarbamate (Dichlormate) and 2,3,5-trichloro-4pyridinot (Pyriclor) has been attributed to the inhibition of $\beta$-carotene synthesis with the concurrent accumulation of $\zeta$-carotene, phytofluene and phytoene (Burns, Buchanan and Carter, 1971). These carotenoids are not capable of protecting the chlorophyll from photooxidative destruction sensitized by the chlorophyll itself (Mathews-Roth and Krinsky, 1970). 
The chloroplastidic $\beta$-carotene may be involved in some way in the protection of the plastids of developing tomato fruit from photosensitized oxidation. Zeaxanthin and its epoxides are derived from $\beta$-carotene in green tomato plant leaves (Glover and Redfearn, 1953). These oxygenated $\beta$-carotene derivatives may be involved in the deactivation of the chlorophyl1-oxygen complex (Blass, Anderson and Calvin, 1959; Yamamoto, Nakayama and Chichester, 1962). Thus the chloroplastidic $\beta$-carotene may serve as a precursor for its oxygenated derivatives involved in photoprotection. The role of the carotenoid pigments synthesized during the ripening of the tomato fruit is still obscure.

B. The Genetics of the Inheritance of Chromoplast Carotenoids in the Tomato Fruit

The carotenoids in the chromoplasts exhibit a wider degree of qualitative and quantitative variability than do carotenoids in the chloroplasts. The greater mutability of chromoplasts compared to the latter organelles has never been satisfactorily explained, especially considering that chromoplasts may be derived from chloroplasts (Frey-Wyssling and Muhlethater, 1965).

Most of the genes studied so far which determine tomato fruit color do not affect the amount and/or kind of carotenoids present in the leaves and green fruit. There are two exceptions: the high pigment gene, $h p^{+} / \mathrm{hp}$, and the ghost gene, $\mathrm{gh}^{+} / \mathrm{gh}$. The recessive mutant allele, $\mathrm{hp}$, increases both the chlorophy11 content and the amount of the different carotenoids in the leaves and green fruit and in ripe fruits (Baker and Tomes, 1964). 
The recessive mutant allele, gh, causes a drastic loss of chlorophyll and colored carotenoids in both leaves and fruits (Mackinney, Rick and jenkins, 1956; Rick, Thompson and Brauer, 1959).

The genotypes of several tomato fruit color mutants are shown in Table 1.

The $r^{+} / r$ gene affects the total amount of carotenoids in the ripe fruit (LeRosen, Went and Zechmeister, 1941; Jenkins and Mackinney, 1955). It was suggested (Mackinney, Rick and Jenkins, 1956) that the recessive allele, $\underline{r}$, blocks the carotenoid pathway prior to phytoene since this polyene does not accumulate in the $\underline{r}$ fruit.

The homozygous recessive allele, $\underline{t}$, causes phytoene, phytofluene, 5 -carotene and neurosporene to accumulate in the fruit (Williams, Britton, Charlton and Goodwin, 1967). The most dramatic effect of the $t^{+} / t$ gene, however, is the accumulation of the poly-cis isomers of lycopene and neurosporene, prolycopene and proneurosporene, in the tt genotype. The $t^{+} / t$ gene may act by determining the spatial configuration of the carotene molecule (Zechmeister and Went, 1948), or it might control à dehydrogenase involved in the conversion of the poly-cis carotenoids to Tycopene (Zechmeister, LeRosen, Went and Pauling, 1941; Mackinney and Jenkins, 1952; Porter and Anderson, 1967).

Jenkins and Mackinney (1955) discovered the apricot gene, at ${ }^{+} / \mathrm{at}$. The recessive allele, at, reduces the total carotenoid content in the fruit and at the same time suppresses lycopene synthesis but not that of 
Table 1

Genotypes of Tomato Fruit Color Mutants

\begin{tabular}{|c|c|c|c|c|c|c|c|c|c|c|}
\hline Color Variety & $r^{+} / r$ & $t^{+} / t$ & $a t^{+} / a t$ & $\mathrm{~B} / \mathrm{B}^{+}$ & $\mathrm{mo}_{\mathrm{B}}^{+} / \mathrm{mo}_{\mathrm{B}}$ & $\mathrm{Del}{ }^{+} / \mathrm{Del}$ & $\operatorname{og}^{C+} / \operatorname{og}^{C}$ & $\mathrm{hp}^{+} / \mathrm{hp}$ & $\mathrm{gh}^{+} / \mathrm{gh}$ & $\mathrm{sh}^{+} / \mathrm{sh}$ \\
\hline Red & + & + & + & $B^{+} B^{+}$ & $\mathrm{mo}_{\mathrm{B}}{ }^{+} \mathrm{mo}_{\mathrm{B}}{ }^{+}$ & + & + & + & + & + \\
\hline Tangerine & + & tt & + & + & + & + & + & + & + & + \\
\hline Apricot & + & + & atat & + & + & + & + & + & + & + \\
\hline High-beta & + & + & + & BB & $\mathrm{mo}_{B} \mathrm{mo}_{B}$ & + & + & + & + & + \\
\hline $\begin{array}{l}\text { Intermediate- } \\
\text { beta }\end{array}$ & + & + & + & BB & $\mathrm{mo}_{\mathrm{B}}{ }^{+} \mathrm{mo}_{\mathrm{B}}{ }^{+}$ & + & + & + & + & + \\
\hline Delta & + & + & + & + & + & DelDel & + & + & + & + \\
\hline Crimson & + & + & + & + & + & + & $\operatorname{og}^{C}{ }_{o g}{ }^{C}$ & + & + & + \\
\hline High Pigment & + & + & + & + & + & + & + & hphp & + & + \\
\hline Low Pigment & $r r$ & + & + & + & + & + & + & + & + & + \\
\hline Ghost & + & + & + & + & + & + & + & + & ghgh & + \\
\hline Sherry & + & + & + & + & + & + & + & + & + & shsh \\
\hline
\end{tabular}

tindicates dominance except in the $\underline{B}^{+} / B$ and $\underline{D e l^{+} / D e l}$ genes where $\underline{B}^{+}$and $\underline{D e l^{+}}$are the recessive alleles, respectively. 
B-carotene. In the $\underline{B}$ fruit, however, atat inhibits the synthesis of $\beta$-carotene (Tomes, Quackenbush and Kargl, 1958) which presumably was produced by cyclization of lycopene (Kohler, Lincoln, Porter, Zscheile, Caldwe11, Harper and Silver, 1947; Lincoln and Porter, 1950; Porter and Lincoln, 1952).

The $\underline{B}^{+} / B$ gene dotermines whether the major carotenoid in the fruit is 1ycopene or B-carotene (Kohler et al., 1947; Lincoln and Porter, 1950). Its effect is modified by another set of independentiy inherited genes, $\mathrm{mo}_{B}^{+} / \mathrm{mo}_{B}$. The dominant allele, $\underline{B}$, causes the accumulation of jarge amolints of $\beta$-carotene in the fruit; the recessive allele, $\underline{B}^{+}$, in the presence of the dominant allele, $\underline{m o}_{B}^{+}$, shifts the pathway to lycopene synthesis. However, when the dominant alleles $\underline{B}$ and $\mathrm{mo}_{B}{ }^{+}$are together, the fruit produces approximately equal amounts of $1 y$ copene and $\beta$-carotene (Tomes, 1963). Tomes, Quackenbush and Kargl (1956) suggested that the function of the $\underline{B}$ alleie is to mediate the formation of the $\beta$-ionone ring.

The $\underline{D e 1^{+} / D \in 1}$ gene appears to control the formation of the $\alpha$-ionone ring (Karg1, Quackenbush and Tomes, 1960). Fruits containing the dominant allele, Del, contain abcut $40 \%$ less carotenoids than the Del $^{+}$tomato and the major carotenoid is $\delta$-carotene.

Substitution of the $\underline{B}$ allele for $B^{+}$in a DelDel genotype results in the reduction of $\alpha$ - and $\delta$-carotenes (Tomes, 1967); the substitution of either $\underline{B}$ or $\underline{\mathrm{Del}}$ for $\mathrm{B}^{+}$or $\underline{\mathrm{Del}}^{+}$, respectively, reduces the lycopene content of the red-fleshed genotypes. Thus the $\mathrm{B}^{+} / \mathrm{B}$ and $\underline{\mathrm{Del}} \mathrm{T}^{+} / \mathrm{Del}$ genes probably 
compete for a common precursor. $\underline{B}$ and Del, however, induces the production of large amounts of $\beta-$ and $\alpha$-ionone ring-containing carotenes only in fruits of the normal red genotypes; they have no effect on the carotenoid distribution in the $\underline{r r}$ fruits. Smali amounts of $\alpha$ - and $\beta$-carotenes are produced when Del is introduced into the atat and tt genotypes (Tomes, 1969).

The recessive allele, gh, of the ghost gene causes an unstable chlorophyll deficiency in the plant. The stems, leaves, flowers ard immature fruit may vary in the degree of pigmentation from completely white to yellow, or green. The ripe fruit, however, is yellow due to the yellow skin pigment. The fruit as well as the stems and leaves contain mainly phytoene. The total carotenoid content of the ripe fruit is approximately normal (Mackinney, Rick and Jenkins, 1956).

The crimson tomato is homozygous for the recessive allele, $\mathrm{og}^{\mathrm{C}}$ (Thompson, Tomes, Wann, McCollum and Stoner, 1965). It increases the lycopene content of the ripe fruit concurrent with a loss of $\beta$-carotene.

The recessive sherry allele, sh, inhibits lycopene synthesis but not that of $\beta$-carotene (Zscheile and Lesley, 1967). Its effect is similar to the $r$ allele in that it reduces the $\beta$-carotene content of the atat fruit.

Al1 the genes which affect tomato fruit color are nuclear genes (Kirk and Tilney-Bassett, 1967), i.e. their inheritance is controlled by the nucleus in contrast to cytoplasmic or extranuclear genes whose inheritance is mediated by extranuclear genomes contained in such cell organelles as the plastids and mitochondria (Gibor and Granick, 1964). 


\section{Biosynthesis of Carotenoids}

Carotenoids share the pathway common to all terpenoids from acetate to isopentenyl pyrophosphate and dimethylallyl pyrophosphate (Goodwin, 1965b,d). Mevalonic acid (Fig. 1) is the first metabolite that is specific to terpenoid biosynthesis in higher plants; once acetate is converied to mevalonic acid, it has no other fate in the system but to be utilized for terpenoid synthesis (Popjak and Cornforth, 1960). Certain microorganisms can utilize leucine as substrate for carotenoid biosynthesis (Chichester, Nakayama, Mackinney and Goodwin, 1955). Comprehensive reviews on terpenoid biosynthes is have been made by Goodwin (1965b, d) and more recently by Porter and Anderson (1967).

Phytoene is the first $\mathrm{C}_{40}$ compound formed from which all the other more unsaturated carotenoids are derived (Fig. 2). It is formed by the "taii-to-tail" dimerization of two molecules of geranylgeranyl pyrophosphate. The latter arises by successive "head-to-tail" condensation of isopentenyl pyrophosphate with dimethylallyl pyrophosphate, geranyl pyrophosphate, and farnesyl pyrophosphate (Fig. 1).

Dimethylallyl pyrophosphate is required for chain initiation (Agronoff, Eggerer, Henning and Lynen, 1959); isopentenyl pyrophosphate is required for chain elongation (Jungalwala and Porter, 1967). Varma and Chichester (1962) and Subbarayan, Kushwaha, Suzue and Porter (1970) reported the incorporation of isopentenyl pyrophosphate by tomáto homogenate into 1ycopene, and by an enzyme preparation from spinach leaves into phyto- 
Figure 1. Modified scheme for the biosynthesis of geranylgeranial pyrophosphate (Goodwin, 1965b,d). 
(50)
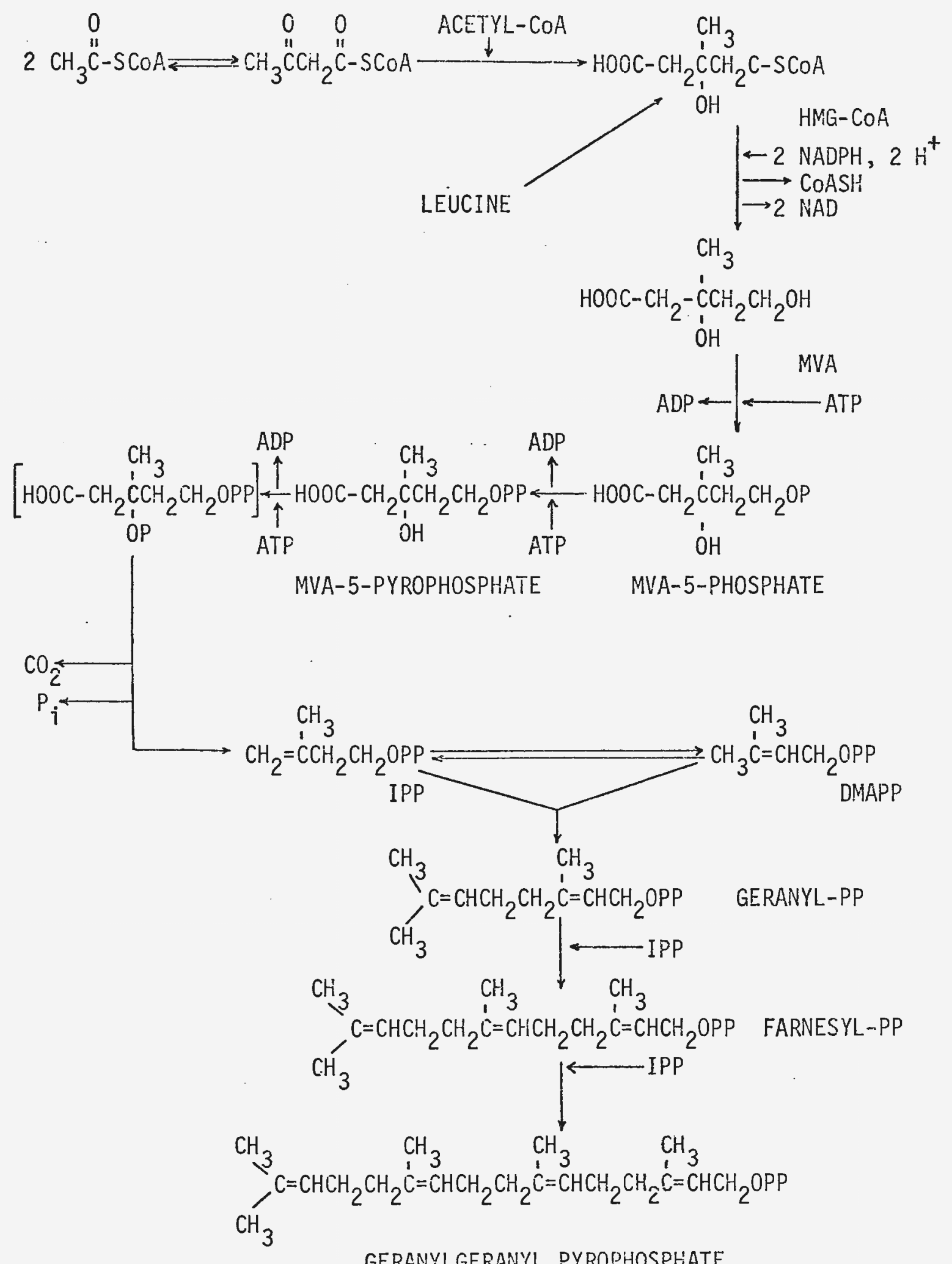

GERANYLGERANYL PYROPHOSPHATE 
Fig. 2. The biosynthesis of acyciic carotenoids (Goodwin, 1965b,d). 


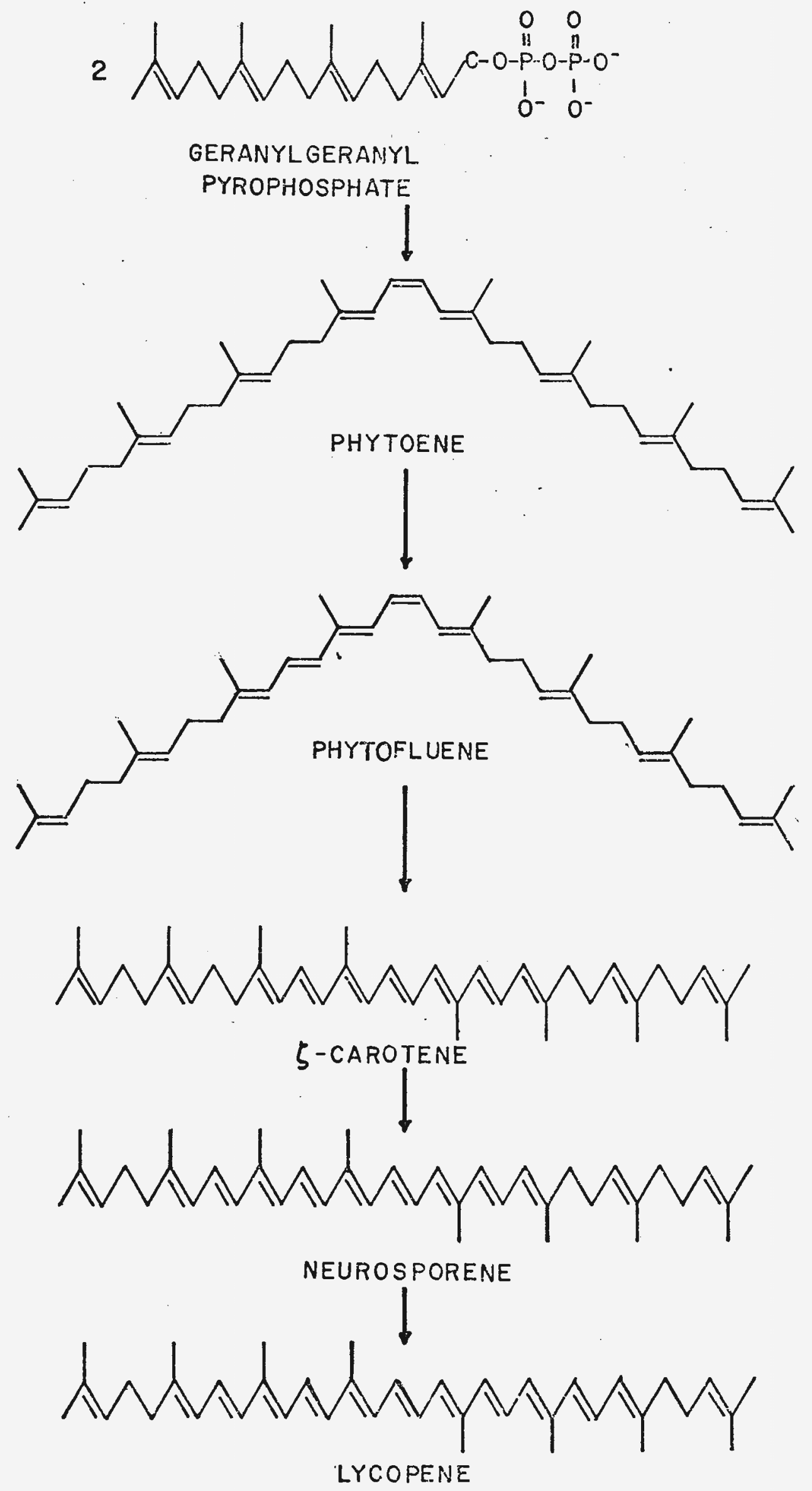


ene, phytofluene and Tycopene. The conversion of geranylgerany? pyrophosphate into phytoene has also been reported (Shah, Feldbruegge, Houser and Porter, 1968).

The condensation steps are stereospecific (Goodwin, 1969). The hydrogen atom eliminated in each step is originally the 45 hydrogen of mevalonic acid. The resulting 4,8,12 and 16 positions in geranylgeranyl pyrophosphate are all trans. In the dimerization of two molecules of geranylgeranyl pyrophosphate, one hydrogen atom is stereospecifically el iminated from each molecule. These are the 5 S hydrogen of mevâlonic acid. However, the double bond formed at the center of the phytoene molecule has the cis configuration (Jungalwala and Porter, 1965). Goodwin (1965) believes that the central double bond in the phytoene molecule is responsible for the absence of cyclic carotenoids with ring structure arialogous to the steroid skeleton.

The exact mechanism of sequential introduction of double bonds has not been established. Rilling (1962) ruled out a hydroxylation mechanism for the introduction of double bonds on the basis that oxygen or an electron acceptor such as $\mathrm{K}_{3} \mathrm{Fe}(\mathrm{CN})_{6}$ is required for the conversion of phytoene and phytofluene to the less saturated members of the series.

Beeler and Porter (1962) reported the enzymic conversion of phytoene to phytofiuerie and to lycopene (Subbarayan et al., 1970). A cell-free enzyme preparation capable of converting al1-trans geranylgeranyl pyrophosphate into phytoene, phytofluene, $\zeta$-carotene, neurosporene and lycopene has been obtained from Phycomyces blakesleeanus mutant by Lee and 
Chichester (1969). Suzue (1961) reported the formation of $\delta$-carotene from phytoene by a cel1-free preparation of Staphylococcus aureus. The conversion of lycopene into cyclic carotenes containing $\alpha$-and/or $\beta-$ ionone rings by plastid preparations from higher plants has been reported (Decker and Uehleke, 1961; We11s, Schelble and Porter, 1964; Kushwaha, Subbarayan, Beeler and Porter, 1969; Hill and Rogers, 1969). Decker and Uehleke (1961) also observed the conversion of $\beta$-carotene into lycopene by leaf chloroplasts.

It has now been unambiguously demonstrated that the more unsaturated carotenoids are formed by dehydrogenation of phytoene. While it is already clear that two enzyme systems catalyze the formation of $\alpha$ - and $\beta$ ionone rings in carotenes and that the isomerizations of $\alpha$-ionone to $\beta$-ionone, or vice versa, do not occur (Goodwin and Williảms, 1965; Williams, Britton and Goodwin, 1967; Goodwin, 1969), the branch point at which ring closure starts is still unresolved and remains the most controversial point in carotenoid biosynthesis. Either neurosporene or lycopene could cyclize to form the $\alpha$ - and $\beta$-ionone residues of the carotene molecule. The possible pathways for these transformations are presented in Fig. 3.

In photosynthetic tissues, there appears to be a compartmentalization of terpenoid biosynthesis (Fig. 4). Terpenoids which are associated with the photosynthetic mechanism in the plastid are formed in greening tissue from $\mathrm{CO}_{2}$ but not from exogenously supplied mevalonic acid (Mercer and Goodwin, 1962, 1963, 1964; Griffiths, Threlfall and Goodwin, 1964; Goodwin, 1965b,d). These include the carotenoids, the phytol side-chain of chlorophyll, the side-chain of plastoquinone, tocopherols and vitamin 
Fig. 3. Alternative pathways for the biosynthes is of cyclic carotenes (Williams, Britton and Goodwin, 1967). 
Scheme A

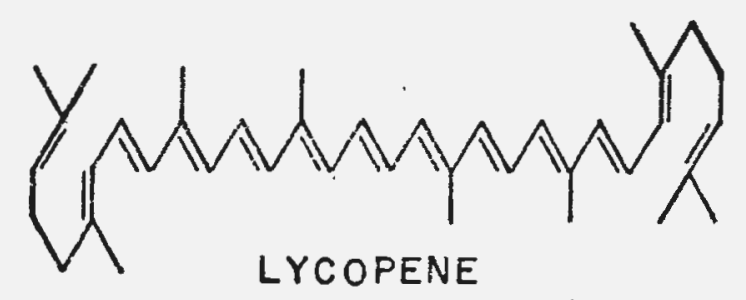

:
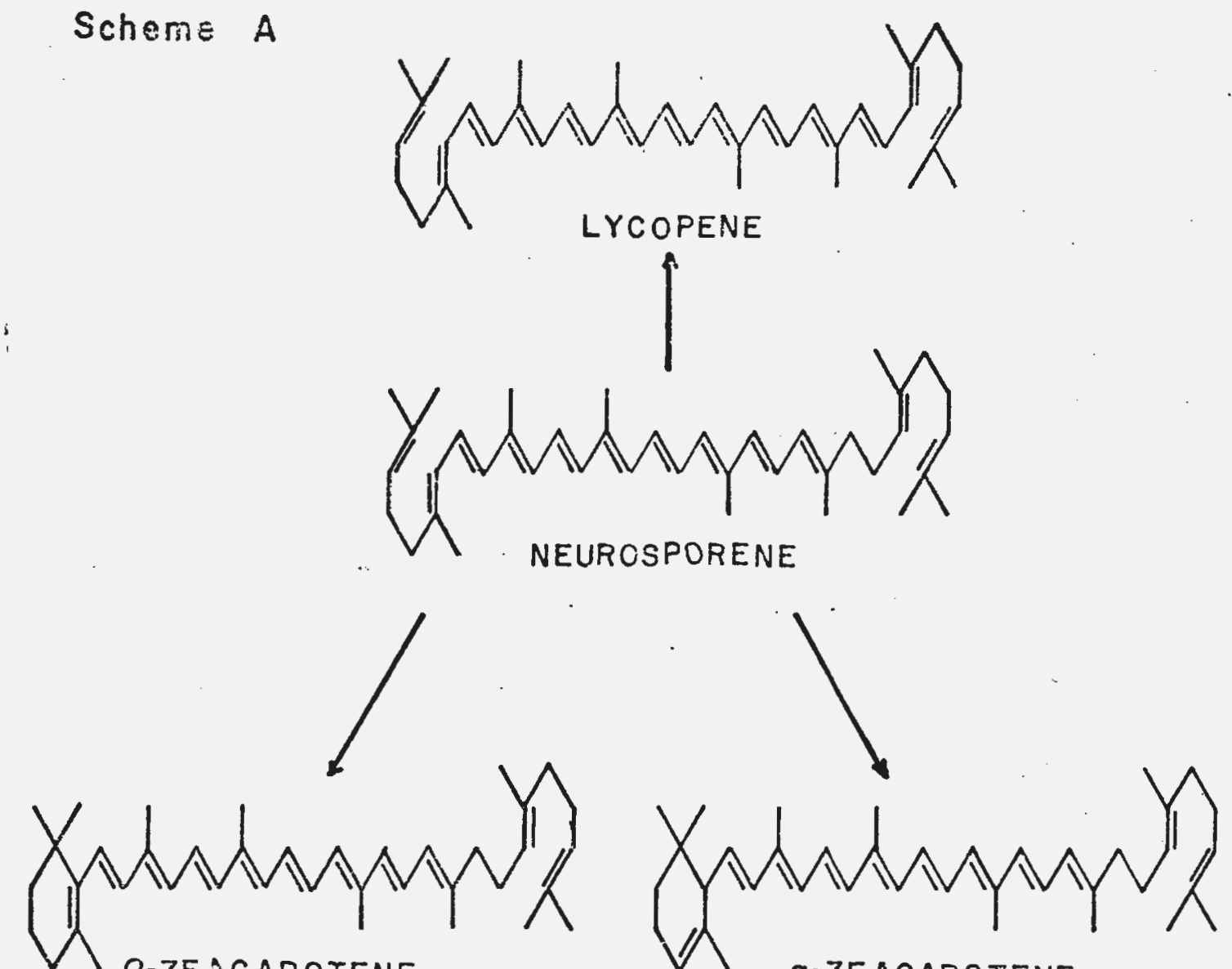
B-ZEACAROTENE

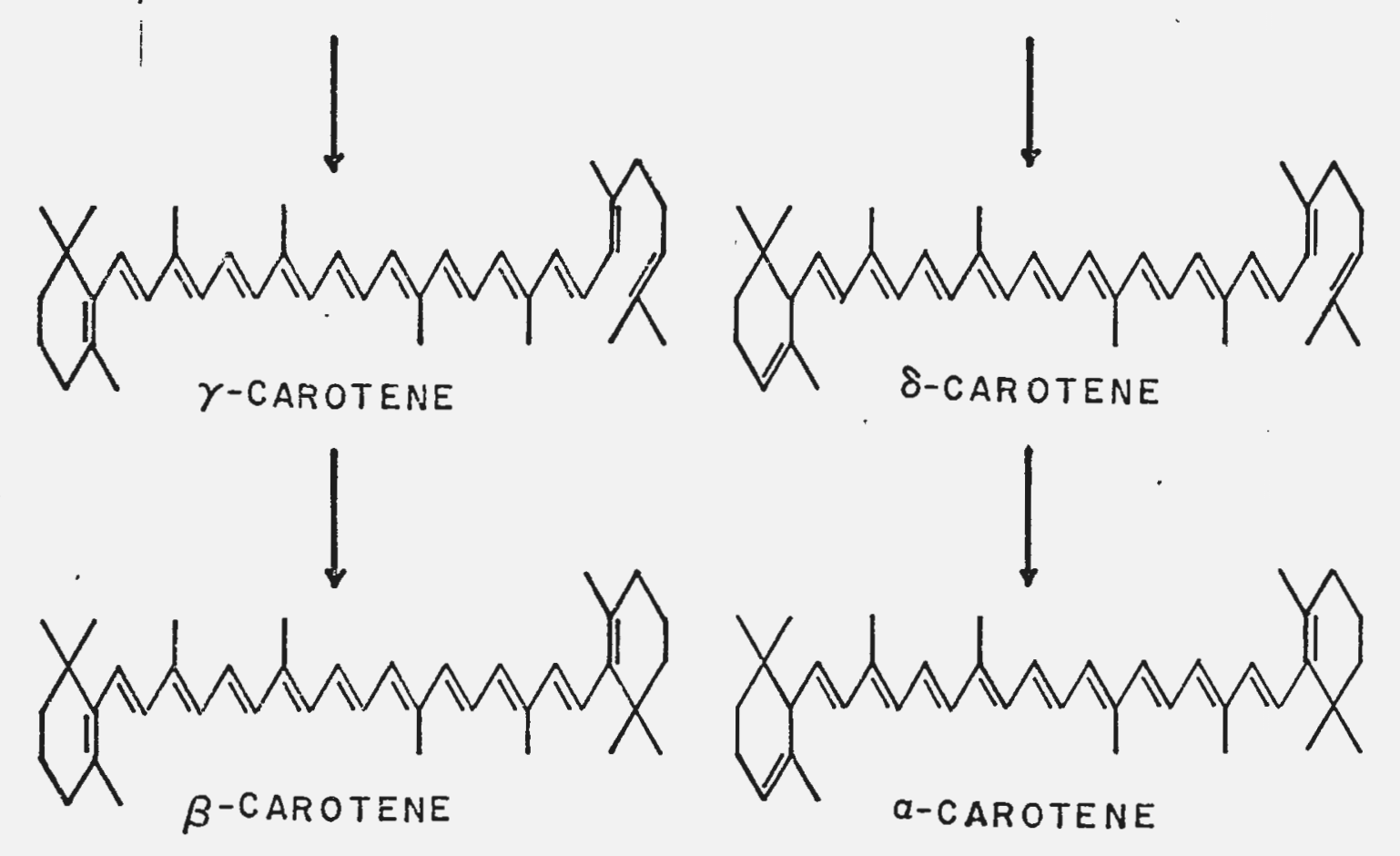


Fig. 3.--continued 
(55)
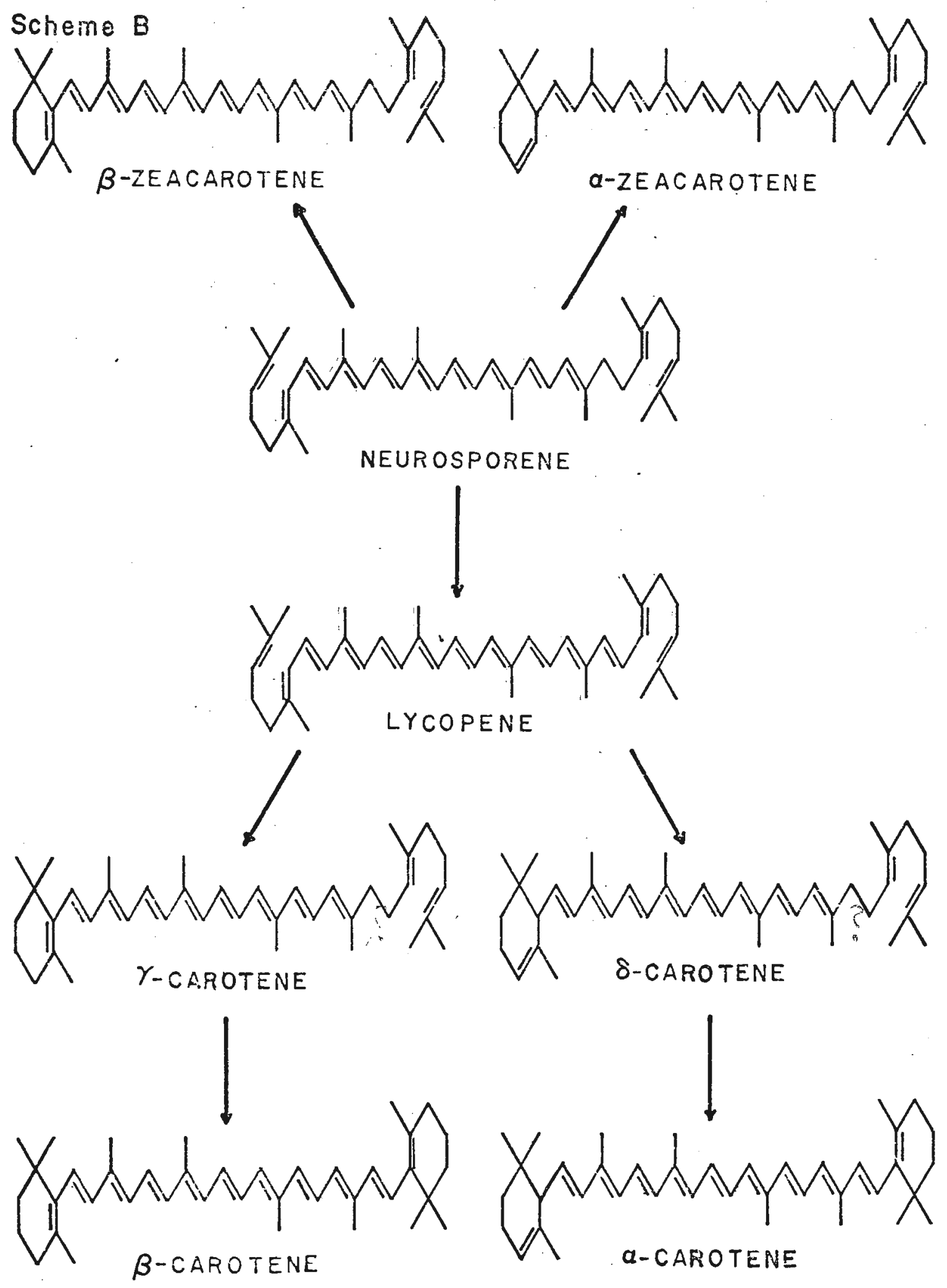
Fig. 4. The proposed scheme for compartmentalization of terpenoid biosynthesis in higher plants (Goodwin, 1965b). 


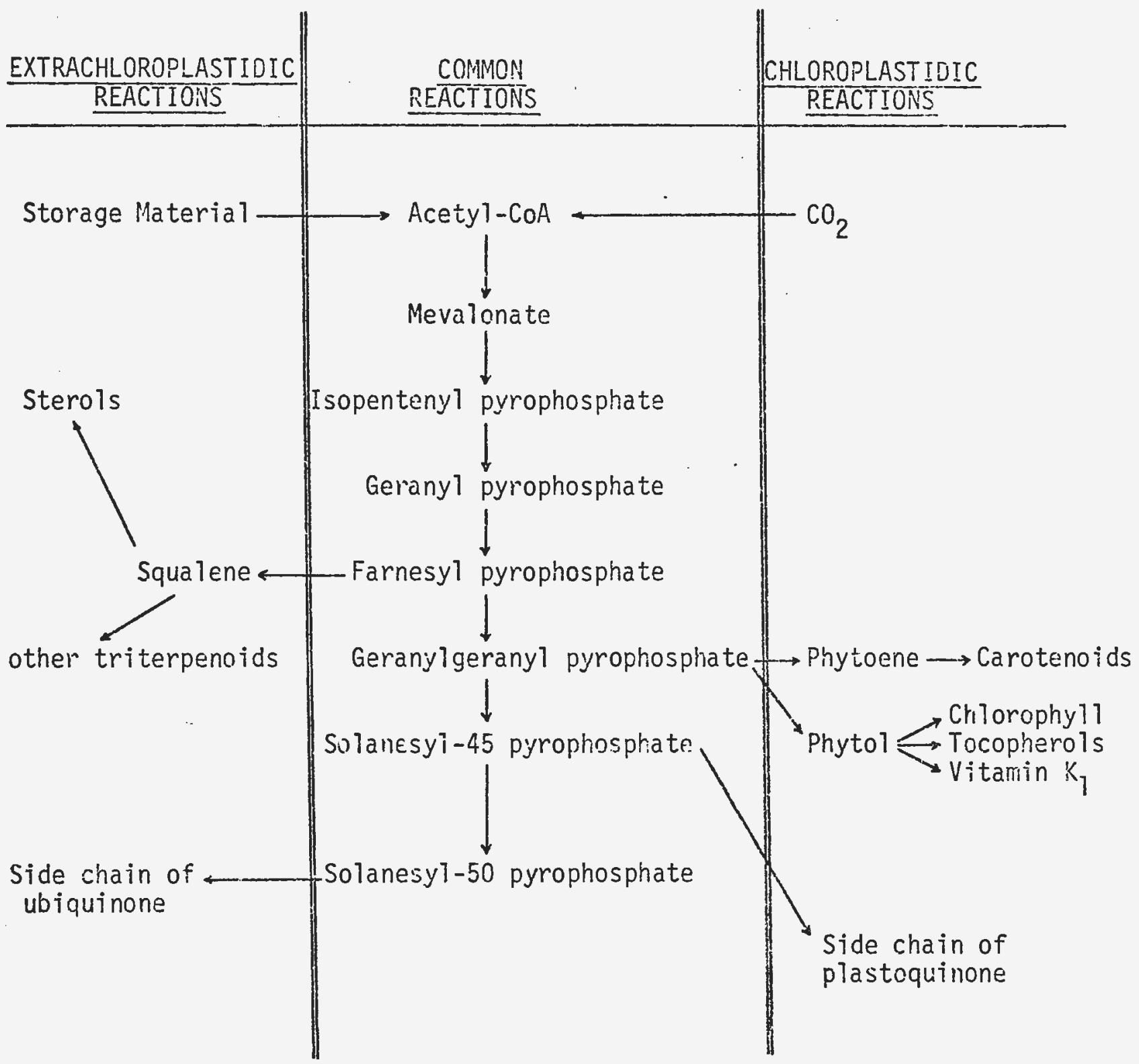


$\mathrm{K}_{1}$. The extrachloroplastidic terpenoids which include squalene, steroids, the side-chain of ubiquinone and other triterpenoids may be formed from mevalonic acid, presumably via isoenzynes of the terpenoid pathway. The plastid membrane is probably impermeable to mevalonic acid but not to $\mathrm{CO}_{2} \cdot$ A combination of enzyme segregation and specific membrane permeability was suggested by Goodwin $(1965 b, d)$ to account for the compartmentalization. Rogers, Shah and Goodwin (1967) described the possible existence of chloroplastidic and extrachloroplastidic mevalonic acid activating enzymes. They also showed (1966) the presence of two mevalonic acid kinases in both green and etiolated leaves differing only in their pH optima. The $\mathrm{pH}$ optimum for the chloroplast mevalonate kinase is at $\mathrm{pH} 7.5$ while that of the extrachloroplastidic kinase is at $\mathrm{pH} 5.5$. Compartmentalization of terpenoid biosynthesis is a relatively common occurrence in biological systems. For example, natural rubber and other terpenoids are both synthesized from isopentenyl pyrophosphate; rubber is poly-cis while terpenoids, such as the carotenoids, are predominantly a17-trans. The formation of isopentenyl pyrophosphate from mevalonic acid occurs in the serum of the latex whereas the polymerization of isopentenyl pyrophosphate takes place almost exclusively on the surface of existing rubber particles (Archer, Audley, Cockbain and McSweeney, 1963) catalyzed by an enzyme distributed between the hydrocarbon surface and the aqueous serum. The farnesyl pyrophosphate synthesized by the serum of rubber latex incorporated the $4 R$ hydrogen of mevalonic acid, while the rubber formed contained only the $4 S$ hydrogen (Archer, Barnard, Cockbain, Cornforth, Cornforth and Popjak, 
1966). Thus in the rubber latex there are probably two enzymes responsible for the production of a11-trans terpenoids and rubber; the trans terpenols are not intermediates in rubber biosynthesis. 


\section{MATERIALS AND METHODS}

\section{A. The Plant Material}

Fruits of the "lutescent", high-beta and tangerine tomato lines were harvested from field-grown plants. The ghost plants were grown in the greenhouse. To obtain sufficient ghost fruits for the study, the plants were sprayed with a 3\% solution of "Blossom-Set" (Science Products Co., Inc., Chicago, Illinois). The spray material contains as active ingredient $0.1389 \%$ B-naphthoxyacetic acid.

The "lutescent" tomato fruits were harvested and graded into the following stages of maturity: Stage 1. White, greenish around the stemend; Stage 2. Frimarily white, slightly lutescent around the stem-end; Stage 3. Lutescent, slight internal pink coloration; and Stage 4. Full yellow, externally visible red coloration at the blossom-end and throughout the center of the fruit.

Each lot was soaked for 1 hour in a 10\% solution of DHSO and ripened subsequently at $27-30^{\circ}$. The corresponding control lots were soaked in distilled water at the same time. Five fruits from each maturity group were removed each day and frozen at $-17^{\circ}$. They were held in the freezer until analyzed.

The high-beta fruits in the DMSO experiment were harvested at the mature green stage. The fruits were similarly treated as above. The samples consisted of 3 fruits for each treatment. The samples were kept in the freezer $\left(-17^{\circ}\right)$ until analyzed. 
In the CPTA experiments, the high-beta fruits were harvested at the turn stage. Ghost fruits containing small areas of green tissue were harvested as soon as the blossom-end turned yellow. Each fruit was injected with $1 \mathrm{ml}$. of either distilled water or a solution containing 4300 ppm of CPTA, and allowed to ripen at $25^{\circ}$ for 12 days. Each treatment sample consisted of 12 high-beta fruits and 32 ghost fruits. Where tissue from the same fruit was used, each fruit was dissected. The red sections were combined and analyzed. The yellow sections of the same fruits served as the control.

Freshly harvested ripe tangerine tomato fruits were used in the isolation of poly-cis $\zeta$-carotene.

B. The Chemicals

The solvents used in the extraction, chromatographic separation, and purification of the carotenoid pigments were all of analytical reagent grade. The solvents were redistilled prior to use. Glass-distilled pentane (b.p. $35-37^{\circ}$, Burdick and Jackson Laboratories, Inc., Muskegon, Michigan) was used in the purification of phytcene.

The adsorbent Sea Sorb 43 (MgO) and Hyflo Super Cel were obtained from Fisher Scientific Company, Medford, Massachusetts; the aluminum oxide, Woe $7 \mathrm{~m}$, used in the purification of the various fractions was obtained from Alupharm Chemicals, New Orleans, La. The silica gel $F_{254}$ was bought from Brinkmann Instruments, Inc., Westbury, i. Y. 11590, as precoated aluminum rol1 $0.2 \mathrm{~mm}$ thick. 
The dimethyl sulfoxide was supplied by Crown Zellerbach Corp., Chemical Products Division, Camas, Washington. The CPTA was a gift of Amchem Products, Inc., Ambler, Pa. 19002.

Diethyl ether was freed from peroxides prior to use by percolating $200 \mathrm{ml}$. through $25 \mathrm{~g}$. of neutral alumina, activity grade I.

C. General Procedure for Quanti tative Analys is of Carotenoid Pigments of the "Lutescent", High-Beta, and Ghost Tomatoes.

1. Pigment Extraction

The samples were removed from the freezer. Each fruit was cut in half across the blossom-end to the stem-end; half of each fruit was returned to the freezer while the other half was cut into smaller pieces. The sample was homogenized in a Waring Blender. A 25-g. aliquot was weighed in a tared aluminum weighing dish and oven-dried at $70^{\circ}$ until the weight of the material remained constant. A 50-g. aliquot of the nomogenate was weighed for pigment extraction.

The pigment was extracted by blending the sample with acetore and petroleum ether (P.E.) under a continuous stream of $\mathbb{N}_{2}$. The homogenate was filtered through a Buchner funnel attached to a vacuum pump. The extraction was repeated until the residue was colorless except for scattered flakes of yellow skin.

The filtrate was washed with distilled water to remove the acetone. The petroleum ether-soluble fraction was saponified with $200 \mathrm{ml}$. of $15 \%$ $\mathrm{KOH}$ in methanol. Saponification was accomplished by heating the mixture 
for 15-20 min. on a steam table in the dark under a continuous stream of $\mathrm{N}_{2}$. The unsaponifiable fraction was transferred to petroleum ether by pouring the methanolic solution into a mixture of petroleum ether and a small amount of acetone in a separatory funnel. Addition of water transferred the pigment to the epiphase. The petroleum ether solution of the pigment was washed several times with large volumes of water until the hypophase was no longer basic. The solution was dried over anhydrous $\mathrm{Na}_{2} \mathrm{SO}_{4}$ and evaporated to dryness prior to chromatography. The ghost tomato fruit extract was chromatographed without prior saponification.

2. Chromatographic Separation

The "Tutescent" and high-beta tomato extracts were taken up in a small amount of petroleum ether and chromatographed on a tightly-packed $18 \times 160 \mathrm{~mm}$. column of $\mathrm{AgO}:$ Super Cel $(1: 2, w / w)$. The chromatogram was developed first with petroleum ether until the phytofiuene band separated from the $\beta$-carotene band. When the two bands were separated, $1 \%$ diethy 1 ether in petroleum ether was added, followed by $2 \%$ diethyl ether in petroleum ether. The chromatogram was developed with this solvent system until the $\gamma$-carotene band separated from the lycopene band. At this point the concentration of diethyl ether was increased to $5 \%$. The column was allowed to develop further before $2 \%$ acetone in petroleum ether was added. $\beta$-Zeacarotene separated from $\gamma$-carotene with this solvent system. Addition of $5 \%$ acetone further resolved the various bands.

The adsorbent plug was extruded after phytofluene was eluted and the various bands were cut from the plug. The pigments were eluted from 
the adsorbent with a mixture of acetone and petroleum ether. Lycopene was washed from the adsorbent with ethanol in petroleum ether. The fractions were evaporated to dryness in a flash evaporator.

In the case of the ghost tomato extract, the chromatogram was initially developed with petroleum ether as before, followed by $100 \mathrm{ml}$. of $2 \%$ acetone in petroleum ether to elute the phytofluene band. The acetone concentration was increased to $5 \%$ which eluted the $\beta$-carotene band. The adsorbent plug was extruded and the other bands were cut from the plug. The pigments were eluted from the adsorbent as described above.

\section{Purification Procedures}

The crude phytoene fraction from the $M g 0: S u p e r$ Cel column was purified by rechromatography on $15 \mathrm{~g}$. of neutral alumina $I$ in a $10 \mathrm{~mm}$. glass column. Fifty $\mathrm{ml}$. of pentane was percolated through the column to wash the adsorbent before the crude phytoene was added. The column was developed initially with $70 \mathrm{ml}$. pentare, followed by $150 \mathrm{ml}$. of $1 \%$ diethyl ether in pentane. Phytoene was eluted from the column with $2 \%$ diethyl ether in pentane. Five $\mathrm{ml}$. volume fractions were collected with a fraction collector. Phytoene usually appeared between fractions 30 and 50 .

Phytofluene was purified by rechromatography on a short column (ca. $18 \times 60 \mathrm{~mm}$.$) of \mathrm{ilg} 0:$ Super Cel $(1: 2, w / w)$. The phytofluene band was eluted from the column with petroleum ether.

$\zeta$-Carotene was present but was not analyzed in experiments using the "lutescent" and high-beta tomatoes. 
The B-zeacarotene obtained from the igo:Super Cel columin generally was not subjected to further purification because of the relatively smail amount of the pigment. However, when it is contaminated with a substantial amount of a $\gamma$-carotene isomer as indicated by the appearance of a peak at $485 \mathrm{~nm}$, the pigment was rechromatographed on basic alumina III. The pigment was eluted from the column with $1 \%$ dietinyl ether in petroleum ether. $\gamma$-Carotene was rechromatograpied on neutral alumina III with petroleum ether as the developing solvent. In subsequent studies with CPTA, the $\gamma$-carotene fraction was purified routinely by thin-layer chromatography (TLC) on silica ge $1 \mathrm{~F}_{254}$ with $1 \%$ diethyl ether as the developing solvent. The less polar $\gamma$-carotene band was cut from the aluminum plate and eluted from the adsorbent with acetone-petroleum mixture.

The lycopene fraction was washed free of ethanol with distilled water. The petroleum ether solution was dried over aniydrous $\mathrm{Na}_{2} \mathrm{SO}_{4}$ and rechromatographed on a short column of neutral alumina III. The lycopene band was eluted from the column with petroleum ether.

The carotenoid concentration in the various fractions obtained from the Mgo:Super Cel chromatogram of ghost tomato extract was estimated spectrophotonetrically without further purification. The spectrum of the crude phytoene fraction did not show contamiriation. Phytofluene was contaminated by a compound absorbing at $278 \mathrm{~nm}$ which could not be removed by rechromatography on $\mathrm{MgO}:$ Super $\mathrm{C} \in \mathrm{l}$. In any case, the contaminant did not affect absorption maxima of phytofluene at 367,347 and $331 \mathrm{~nm}$. 
The $\zeta$-carotene is the total of two $\tau$-carotenes differing in adsorptivity on the column. One band was adsorbed just above the $\beta$-carotene band, the other just below $\gamma$-carotene. The two fractions showed identical absorption spectra with $\lambda_{\max }$ at 423,398 and $377 \mathrm{~nm}$.

$\gamma$-Carotene was not analyzed routinely because of the small amount of the pigment. Its identity was verified when $500 \mathrm{~g}$. of ghost tomato fruits were used. Lycopene was relatively free from contamination.

D. Extraction and Chromatographic Procedures for the Isolation of Poly-cis

5-Carotene from the Tangerine Tomato

Thirty grams of tissue from freshly harvested tangerine tomato fruit were extracted with acetone-petroleum ether as usual under a continuous stream of $\mathbb{N}_{2}$. The extract was either chromatographed after washing the acetone out or saponified with $10 \% \mathrm{KOH}$ in methano1. Saponification was accomplished by evaporating the petroleum ether in a flash evaporator to transfer the pigment into the methanolic solution. The unsaponifiable material was transferred to petroleum ether after 15 minutes, dried over arihydrous $\mathrm{Na}_{2} \mathrm{SO}_{4}$, and chromatographed on a $22 \times 360 \mathrm{~mm}$. column of $\mathrm{MgO}$ : Super $\operatorname{Cel}(1: 2, w / w)$. The chromatogram was first developed with $2 \%$ acetone in petroleum ether. The acetone concentration was increased to $5 \%$ and finally to $10 \%$.

The adsorbent plug was extruded and the zone below the cis $\zeta$-carotene band was cut together with the faint $\beta$-carotene zone. The pigments were eluted from the adsorbent with acetone-petroleum ether, evaporated to 
dryness and rechromatographed on a $12 \times 150 \mathrm{~mm}$. column of neutral grade alumina II. The chromatogram was developed with increasing concentrations of diethyi ether in petroleum ether. The poly-cis $\zeta$-carotene was eluted from the column together with the $\beta$-carotene band with $5 \%$ diethyl ether. The eluate was evaporated to dryness and purified by TLC on silica gel $F_{254}$ plates with petroleum ether as developing solvent. The yellow band adsorbed below the $\beta$-carotene band is the poly-cis $\zeta$-carotene.

Alternatively, the eluate from the MgO:Super Cel column was first. purified by TLC to remove the 8 -carotene. The zone containing the polycis $\zeta$-carotene was eluted from the adsorbent witin acetone-petroleum ether, evaporated to dryness, and rechromatographed on a short column of neutral grade alumina II to remove a contaminating $\beta$-zeacarotene-like pigment. E. Pigment Identification

The various carotenoids were identified on the basis of their position on the MgD:Super Cel column and their absorption spectra (Davis, 1965). F. Spectrophotometric Analys is

The absorption spectra were recorded from petroleum ether (b.p. $35-$ $\left.50^{\circ}\right)$ solutions of the various carotencids with a Cary 15 recording spectrophotometer, with the exception of phytoene whose spectra were recorded from either pentane or petroleum ether. The $E_{1 \mathrm{~cm}}^{1 \%}$ values and waveiengths used in the quantitative estimation of the various fractions are given beiow. 


$\begin{array}{llr} & \lambda_{\max }{ }^{\mathrm{nm}} & \mathrm{E}_{1 \mathrm{~cm}}^{i \%} \\ \text { Phytoene } & 285 & 1250 \\ \text { Phytofluene } & 348 & 1350 \\ \text { 5-Carotene } & 400 & 2270 \\ \text { Lycopene } & 472 & 3450 \\ \beta \text {-Zeacarotene } & 428 & 2570 \\ \gamma \text {-Carotene } & 462 & 3100 \\ \beta \text {-Carotene } & 451 & 2505 .\end{array}$

The amount of carotenoid in the solution was then calculated as follows:

$$
m g .=\frac{\text { Absorbance } \times \text { Total Volume } \times \text { Dilution Factor }}{E_{1 \% \mathrm{~cm}}^{1 \%} \times 0.1}
$$

Quantitative estimation of the poly-cis $\zeta$-carotene was made from the equilibrium mixture of stereoisomers after the poly-cis pigment was subjected to iodine catalysis using the corresponding $E_{1 \%}^{1 \%}$ value for the all-trans $\zeta$-carotene at $400 \mathrm{~nm}$.

G. Iodine Catalysis

One to two drops of a dilute solution of iodine in petroleum ether was added to the pigment solution in a glass-stoppered quartz cell which was subsequentiy illuminated for ca. $10 \mathrm{sec}$. by exposure to direct sunlight, or by exposure to fluorescent light for ca. $30 \mathrm{sec}$. The absorption spectrum of the equilibrium mixture was then recorded. 


\section{DISCUSSION}

The results with DMSO and CPTA on ripening detached tomatoes did not unequivocally prove that neurosporene is the only substrate for the cyclization of carotenes. It should be pointed out, however, that the data obtained are contrary to the suggestion that in the tomato fruit lycoperie cyclizes to B-carotene (Lincoln and Porter, 1950; Porter and Lincoln, 1952; Tomes, Quackenbush and Karg1, 1958; Porter and Anderson, 1962).

A reappraisal of the results of studies on the genetics of the inheritance of several genes affecting tomato fruit color in conjunction with the results of ultrastructural studies on plastid development in the tomato fruit would lead to the conclusion that in the tomato fruit either separate or parallel pathways exist for the synthesis of $\beta$-carotene of the chloroplasts and the major carotenoids of the chromoplasts.

The apricot gene, for example, in the homozygous recessive form, atat, inhibits lycopene formation; the $\beta$-carotene level in the atat fruit is the same as that found in the at $^{+}$at ${ }^{+}$fruit (Jenkins and Mackinney, 1955; Tomes, Quackenbush and Karg1, 1958). The total carotenoid content of the apricot fruit is only about 10\% of the total accumulation in the red genotype, suggesting that the pigment lost is mainly lycopene and the associated polyenes. A logical explanation of this observation is that $\beta$-carotene and lycopene are formed through separate pathways and that the at allele preferentially inhibits the lycopene pathway but not the other. 
The $\underline{B}$ allele, analogously, has no effect on the $\beta$-carotene fraction in the tangerine tomato (Tomes, Quackenbush and Kargl, 1956). The $\beta$-carotene fraction which is not affected by the at and $\underline{B}$ alleles could be the structural carotenoid associated with the chlorophyll in the chloroplasts of the green tissue. This struciural $\beta$-carotene may be that pigment required for the formation of the nornal ?amellar system of maturing chloroplast as well as for the protection of chlorophyll and the grarla structure against photooxidative destruction (Walles, 1967). 'It may also be the precursor for zeaxanthin which is invoived in the protection of the photosynthetic apparatus against photodestruction (Blass. Anderson and Calvin, 1959; Yamamoto, Nakayama and Chichester, 1962). This B-carotene could be

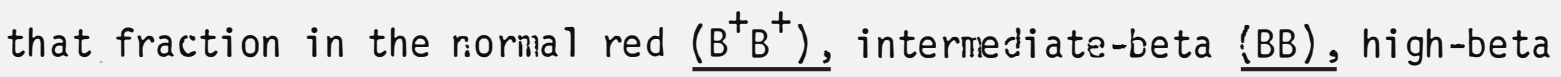

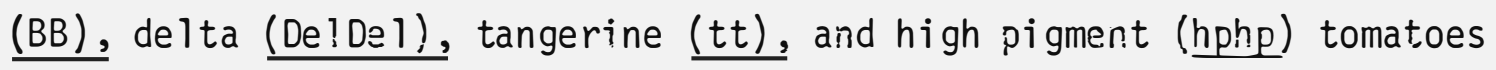
which is not affected by ripening at $32^{0}$ iGoodwin and Jamikorn, 1952; Tomes, Quackenbush and Kargl, 1956; Tomes, 1963); by DMS0 treatment (Raymundo, Griffiths and Simpson, 1967, 1970) and irradiation (Burns and Desrosier, 1957).

Chloroplasts of green tissues of higher plants are morphologically similar (Kirk and Tilney-Bassett, 1967). They contain essentially the same pigment systems, namely, chlorophylls and carotenoids. The fine structure of the tomato fruit chloroplast is comparable to that of the leaf chloroplast (Lefort, 1957; Rosso, 1968). The chromoplasts of the ripe tomatc fruit develop from the chloroplasts of the green fruit and do 
not originate from undifferentiated plastids (Rosso, 1968; Harris and Spurr, 1959). The genes which determine tomato fruit color, with a few exceptions, do not affect the amount and/or kind of carotenoids in the leaves and green fruits. The genes that control carotenogenesis in the two organs appear to be inherited independently. Furthermore, mutations in the chloroplasts do not affect the pigment composition of the chromoplasts, and vice versa (Kirk and Tilney-Bassett, 1967). The leaves and green fruits of the tangerine tomato, $\underline{t t}$, for example, do not contain the characteristic poly-cis carotenoids that accumulate in the ripe fruit. The low total pigment gene, $\underline{r}^{+} / r$, does not affect the carotenoid content of the green leaves and green fruits even though in the low pigment tomato, $\underline{r}$, the ripe fruit contains only about $5 \%$ of the total carotenoids of the $\underline{r^{+} r^{+}}$fruit.

There is very little variation in carotenoid content of the green fruit amiong the various tomato fruit color mutants. In fact, the $\beta$-carotene content of the green fruit of the normal red $\left(B^{+} B^{+}, \underline{r}^{+} r^{+}\right)$, the high-beta

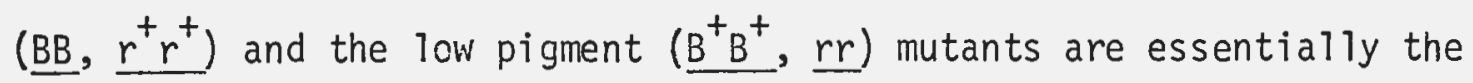
same, i.e. $2.9 \pm 6,25 \pm 5$ and $26 \pm 6 \mathrm{ug} / \mathrm{g}$ dry weight, respectively (Harris and Spurr, 1969). On ripening, more $\beta$-carotene is synthesized in the normal red $(67 \pm 7 \mathrm{ug} / \mathrm{g})$ and in the high-beta mutant $(675 \pm 315 \mathrm{ug} / \mathrm{g})$ while in the low pigment mutant $(7 \pm 1 \mathrm{ug} / \mathrm{g})$ further synthesis of $\beta$-carotene is terminated and the structural $\beta$-carotene is degraded in the transition from chloroplasts to chromoplasts (Harris and Spurr, 1969a). This loss of 
structirai B-carotene may be characteristic of the $\underline{r^{+} / r}$ gene because substitution of $\underline{r}$ for $\underline{r}^{+} r^{+}$in the normal red, tangerine, apricot and intermediate-beta lines resulted in the reduction of $\mathrm{B}$-carotene concentration to the level found in the low pigment, rr, mutant (Jenkins and Mackinney, 1955; Mackinney, Rick ard Jenkins, 1956; Tomes, Quackenbush and Kargl, 1958). Thus $\underline{r}^{+} / r$ gene probabiy controls the mechanism which derepresses the genes for the synthesis of proteins necessary for plastid transformation. The lutescent gene, $\underline{1}^{+} / 1$, might then impose. a restriction on the extent to which $\beta$-carotene synthesis can progress. The stimulus is prodably transmitted from the leaves because in detached Stage 2 fruits, B-carotene synthesis appeared to be still in progress at the termination of the experiment. In the more mature fruit (stage 3 ) the maximum amount of $\beta$-carotene was attained after 3 days of ripening (cf. Tables I. 1 and I. 2).

It is conceivable that abscisic acid, which innibits the synthesis of gibberellins (Wareing, El-Antably, Good and Manuel, 1967) and isoprenoid plastid lipids such as carotenoids, chlorophylls and lipophilic benzoquinones (Mercer and Pughe, 1969; Lichtenthaler and Becker, 1970), influences this activation process in the plastids. Abscisic acid is present in the tomato fruit (Dorffling, 1970). Recently, Khudairi and Arboleda (1971) reported that lycopene synthesis increased in ripening detached tomato fruit treated with abscisic acid. Gibberellic acid, on the other hand, is known to inhibit lycopene synthesis in ripening tomato fruit (Dostal and Leopold, 1967). 
An inhibitor with biological activity approaching that of abscisic acid has been isclated as one of the products of the photolysis of vioiaxanthin (Taylor and Burden, 1970). Taylor and Smith (1967) have sliggested that carotenoids may be the natural precursors of abscisic acid.

Neither ripening at high temperature nor any of the common mutant genes which affect tomato fruit color could significantly reduce the residual $\beta$-carotene fraction. It is possible that the mechanism that controls its synthesis is associated closely with the control mechanism for chlorophyll sunthesis (Bogorad, 1965; Lascelles, 1965). Any condition which results in an increase in chlorophyll synthesis will proportionately increase the synthesis of this $\beta$-carotene fraction. Thus the high pigment gene, $\mathrm{hp}^{+} / \mathrm{hp}$, increases the $\beta$-carotene concentration in both green leaves and fruit because the chlorophy 11 content increased (Baker and Tomes, 1964). Similarly, the $\beta$-carotene content of the ghost tomato, ghgh, varies with the amount of chlorophyll present in the tissue (Mackinney, Rick and Jenkins, 1956).

The parenchymatous cells of the locular tissue of the tomato fruit are ontogenetically different from the parenchymatous cells of the carpel walls (Cocking and Gregory, 1963). Differences in the carotenoid distribution between these two tissues have been observed (Jenkins and Mackinney, 1955; Thompson, Tomes, Wann, McCollum and Stoner, 1965). In the normal red tomato, there is more $\beta$-carotene but less lycopene in the locular tissue than in the pericarp. When $\underline{o g}^{c+} \circ g^{c+}$ is replaced by $\mathrm{og}^{\mathrm{C}} \circ \mathrm{g}^{\mathrm{C}}$ as in 
the crimson tomato, the concentration of iycopene in both tissues increased but the $\beta$-carotene level decreased so that the $\beta$-carotene content of the locular tissue dropped to about the same level as that found in the pericarp. The significance of these findings in relation to the biosynthesis of carotenoids in the tomato fruit is presently not known.

The synthesis of $\delta$ - and $\alpha$-carotene fractions is enhanced by the introduction of the Del allele into the BB genotype (Tomes, 1967). Reciprocally, substitution of $\underline{B}$ for $\underline{B}^{+}$in the DelDel genotype increases $\alpha$-carotene synthesis but reduces $\delta$-carotene accumulation. The reduction in $\delta$-carotene accumulation on the incorporation of $\underline{B}$ into the DelDel genotype suggests that either $\delta$-carotene is not the precursor for $\alpha$-carotene contrary to the suggestion by Williams et al. (1967), or that the B allele shifts the equilibrium between $\delta$ - and $\alpha$-carotene toward $\alpha$-carotene. Such a shift would be predicted in the presence of $\underline{B}$ in the Del fruit if the function of the $\underline{B}$ enzyme is to mediate the formation of the $\beta$-ionone ring (Tomes et all., 1956; Tomes, 1964). The B enzyme is probably non-specific and would catalyze the formation of a $\beta$-ionone ring in the end of a carotene molecule with a completed chromophore, i.e. neurosporene, $\gamma$-carotene, $\delta$-carotene, and for that matter, lycopene when made available; $\zeta$-carotene, $\alpha$-zeacarotene and $\beta$-zeacarotene would not be suitable substrates for the $\underline{B}$ enzyme. Alternatively, introduction of the Del allele into the $\underline{B B}$ genotype enhances $\alpha$-carotene accumulation probably because more $\gamma$-carotene (Tomes, et al., 1954; Tomes, 1963; Raymundo, Griffitins and Simpson, 1970) is available as substrate into which Del can add an a-ionone ring. 
A scheme for the biosynthesis of lycopene and the cyclic carotenes in ripening tomato fruit would be as shown in Figure 5. $\varepsilon$-Carotene accumulates to a limited extent in the DElDel genotype (Kargl et al., 1960); Tomes $(1967,1969)$ did not analyze for $\alpha$-zeacarotene, $\beta$-zeacarotene and $\varepsilon$-carotene. The synthesis of a-zeacarotene is probably enhanced in the DelDel fruit, analogous to the effect of the $\underline{B}$ allele on s-zeacarotene accumulation in the $\underline{B B}$ fruit (Raymundo $\underline{\underline{t}}$ al., 1970).

In summary, it would appear on the basis of the results of the present investigation in conjunction with the earlier genetic and ultrastructural studies on chromoplast development in the tomato fruit that the chloroplastidic $\beta$-carotene may be synthesized independently via parallel pathways with that of the chromoplast carotenoids. The $\beta$-carotene synthesized by ripening normal red tomato fruit is formed by a "carry-over" pathway from the green fruit. The large amounts of $B$-carotene which accumulate in ripening high-beta tomato is probably syntinesized by the pathway operating during the transformation of chloroplasts to chromoplasts. 


\section{BIBLIOGRAPHY}


Cuhmingy)

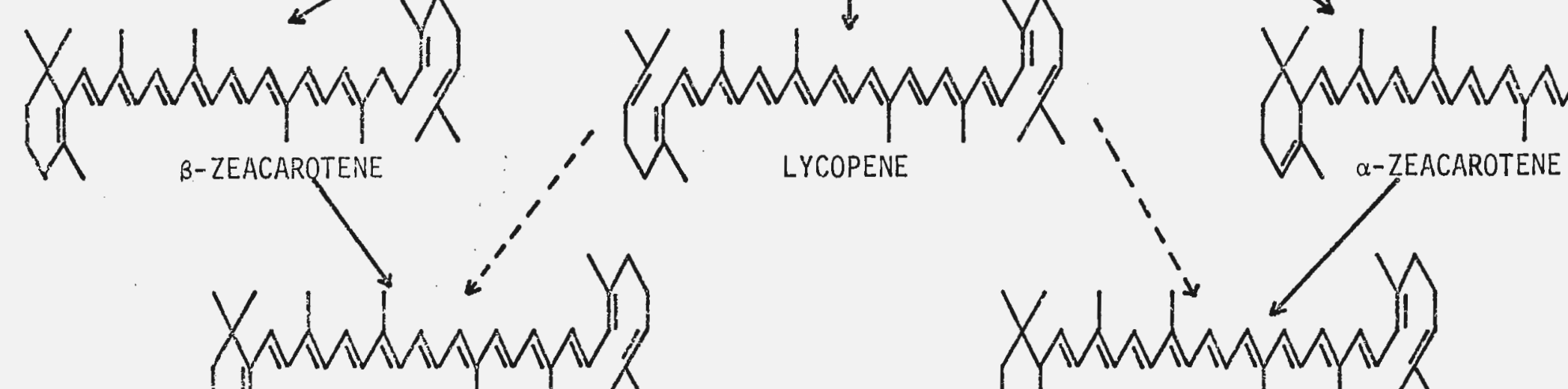

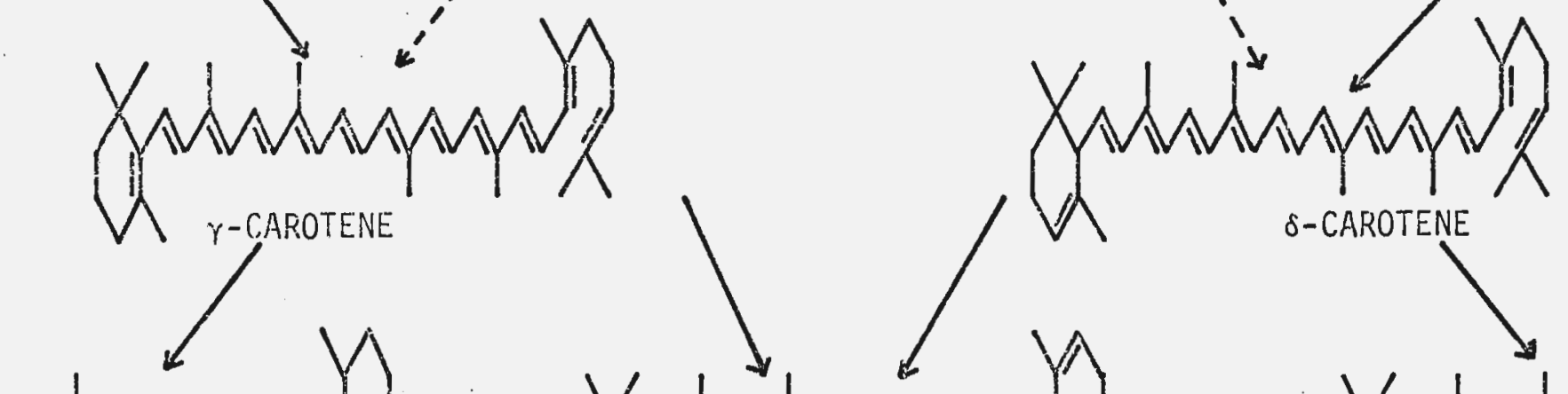

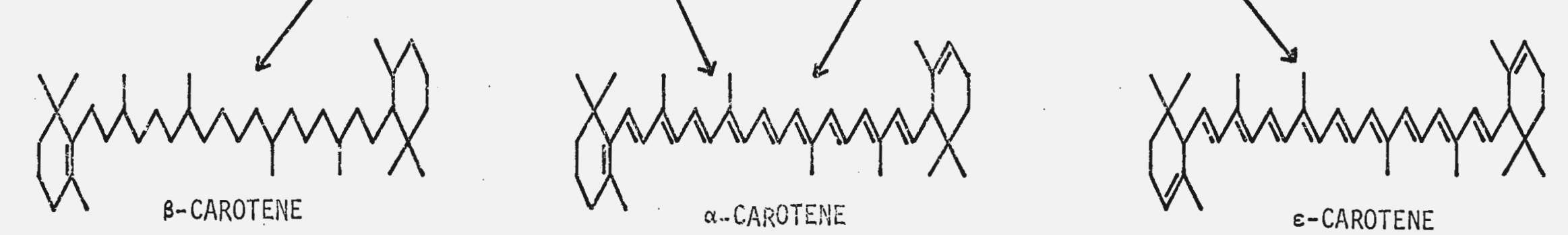


Figure 5. A scheme for the biosynthesis of lycopene and the cyclic carotenes in the tomato fruit. 
Agranoff, B. W., Eggerer, H., Henning, U. and Lynen, F. 1959. Isopentenol pyrophosphate isomerase. J. Amer. Chem. Soc. 81:1254-1255.

Ancierson, I. C. and Robertson, D. S. 1960. Role of carotenoids in protecting chlorophyll from photodestruction. Plant Physiol. 35:531-534.

Anderson, I. C. and Robertson, D. S. 1963. Chlorophyll and carotenoid contents of some pigment mutants of corn. Plant Physiol. 38:iii.

Archer, B. L., Audley, B. G., Cockbain, E. G. and McSweeney, G. P. 1963. The biosynthes is of rubber. Incorporation of mevalonate and isopentenyl pyrophosphate into rubber by Hevea brasiliensis-latex fractions. Biochem. J. 89:565-574.

Archer, B. L., Barnard, D., Cockbain, E. G., Cornforth, J. W., Cornforth, R. H. and Popjak, G. 1966. The stereochemistry of rubber biosynthesis. Proc. Royal Soc. London Ser. B 163:519-523.

Baker, L. R. and Tomes, M. L. 1964. Carotenoids and chlorophylls in two tomato mutants and their hybrids. Proc. Amer. Soc. Hort. Sci. 85: 507-513.

Beeler, D. A. and Porter, J. $W_{4}$ 1963. Specific radioactivities of carotenes synthesized from $C^{14}$-labeled terpenol pyrophosphates by isolated tomato plastids. Arch. Biochern. Biophys. 100:167-170.

Blass, U., Anderson, J. M. and Calvin, M. 1959. Biosynthesis and possible functional relationships among the carotenoids; and between chlorophyl1 a and chlorophy 11 b. Plant Physiol. 34:329-333.

Bogorad, 1. 1965. Chlorophyll biosynthesis. In Chemistry and Biochemistry of Plant Pigments (Edited by T. W. Goodwin), pp. 29-74, ilew York: Academic Press.

Burnett, J. H. 1965. Function of carotenoids other than in photosynthesis. In Chemistry and Biochemistry of Plant Pigments (Edited by T. W. Goodwin), pp. 357-380, New York: Academic Press.

Burns, E. R., Buchanan, G. A. and Carter, M. C. 1971. Inhibition of carotenoid synthesis as a mechanism of action of Amitrole, Dichiormate, and Pyriclor. Plant Physiol. 47:144-148.

Burns, E. E. and Desroisier, N.W. 1957. Maturation changes in tomato fruits induced by ionizing radiation. Food Tech. 11:313-316. 
Chance, B. and Sager, R. 1957. Oxygen and light induced oxidations of cytochrome, flavoprotein, and pyridine nucleotide in a Chlamydomonas mutant. Plant Physiol. 32:548-561.

Chichester, C. O. and Maxwe 11, W. A. 1969. The effects of high intensity visible and ultraviolet light on the death of microorganisms. Life Sci. Space Res. 7:11-18.

Chichester, C. 0., Nakayama, T. 0. M., Mackinney, G. and Goodwin, T. W. 1955. Incorporation of labeled leucine into carotene by Phycomyces. J. Biol. Chem. 214:515-517.

Claes, H. 1954. Analyse der biochemischen Synthesekette fur Carotinoide mit Hilfe von Chlorella Mutanten. Z. Naturforschg. 9b:461-469.

Claes, H. 1956. Biosynthese von Carotinoiden bei Chlorella. 2. Mitt.: Tetrahydrolycopin und Lycopin. Z. Naturforschg. 11b:260-266.

Claes, H. 1957. Biosynthese von Carotinoiden bei Chlorella. III. Untersuchungen uber die lichtabhangige Synthese von $\alpha$ - und $\beta$-Carotin und Xanthophyllen bei der Chlorella-Mutante 5/520. Z. Naturforschg. $12 \mathrm{~b}: 401-407$.

Claes, H. and Nakayama, T. O. M. 1959. Isomerization of poly-cis carotenes by chlorophyll in vivo and in vitro. Nature 183:1053.

Cocking, E. C. and Gregory, D. W. 1963. Organized protoplasmic units of the plant cel1. I. Their occurrence, origin, and structure. J. Experimental Bot. 14:504-511.

Coggins, C. W., Jr., Henning, G. L. and Yokoyama, H. 1970. Lycopene accumulation induced by 2-(4-chlorophenylthio)-triethylamine hydrochloride. Science 168:1589-1590.

Davies, B. H. 1961. The biosynthes is of carotenoids in Rhizophlyctis rosea. Biochem. J. $80: 48 p$.

Davies, B. H. 1965. Analys is of carotenoid pigments. In Chemistry and Biochemistry of Plant Pigments (Edited by T. W. Goodwin), pp. 489532, New York: Academic Press.

Davies, B. H. 1970. A novel sequence for phytoene dehydrogenation in Rhodospirillum rubruin. Biochem. J. 116:93-99.

Davies, B. H., Villoutreix, J., Williams, R. J. H. and Goodwin, T. W. 1963. The possible role of $\beta$-zeacarotene in carotenoid cyclization. Biochem. J. 89:96p. 
Davis, J. B., Jackman, L. M., Siddons, P. T. and Weedon, B. C. L. 1966. Carotenoids and related compounds. Part XV. The structure and synthes is of phytoene, phytofluene, $\zeta$-carotene, and neurosporene. J. Chem. Soc. (C):2154-2165.

Davis, J. B., Jackman, L. M., Siddons, P. T. and Weedon, B. C. L. 1961. The structures of phytoene, phytofluene, $\zeta$-carotene, and neurosporene. Proc. Chem. Soc. London 261-263.

Decker, K. und Uehieke, H. 1961. Eine enzymatische Isomerisierung von Lycopin und B-Carotin. Hoppe-Seyl. Z. physiol. Chem. 323:61-71.

Dorffling, K. 1970. Quantitativ Veranderungen des Abscisinsauregehal tes wahrend der Fruchtenwicklung von Solanum lycopersicum L. Planta (Berl.) 93:233-242.

Dostal, H. C. and Leopold, A. C. 1967. Gibberellin delays ripening of tomatoes. Science 158:1579-1580.

Dworkin, M. 1959. Function of carotenoids in photosynthetic bacteria. Nature 184:1891-1892.

Eugster, C. H., Garbers, C. F. und Karrer, P. 1952. Carotinoidsyntheser. XIII. Uber zwei isomere cis-B-Carotine mit cis-Konfiguration and "behinderten" Doppelbindungen. Helv. Chim. Acta 36:1373-1383.

Faludi-Daniel, A. and Lang, F. 1964. Characteristics of chloroplast mutants with abnormal carotenoid synthesis. Tudomany-Egyetem, Anna 1. Sect. Biol. (Budapest) 7:77-80.

Foote, C. S. 1968. Mechanisms of photosensitized oxidation. Science $162: 963-970$.

Frey-Wyssling, A. and Muhlethaler, K. 1965. U1trastructural Plant Cytology with an Introduction to Molecular Biology. New York: Elsevier PubT. Co.

Gibor, A. and Granick, S. 1964. Plastids and mitochondria: Inneritable sy'stems. Science 145:890-897.

Glover, J. and Redfearn, E. R. 1953. Biosynthesis of $\left[{ }^{14} \mathrm{C}\right] \mathrm{B}$-carotene. Biochem. J. 54:viii.

Goodwin, T.W. 1965a. Distribution of carotenoids. In Chemistry and Biochemistry of Plant Pigments (Edited by T. W. Goodwin), pp. 12 i142, New York: Academic Press. 
Goodwin, T.W. 1965b. The biosynthesis of carotenoids. In Chemistry and Biochemistry of Plant Pigments (Edited by T.W. Goodwin), pp. T43173, New York: Academic Press.

Goodwin, T. W. 1965c. Regulation of terpenoid synthesis in higher plants. In Biosynthetic Pathways in Higher Plants (Edited by J. B. Pridham. and T: Swain), pp. 57-71, New York: Academic Press.

Goodwin, T.W. 1965d. The biosynthesis of carotenoids. In Biosynthetic Pathways in Higher Plants (Edited by J. B. Pridham and T. Swain), pp. 37-55, New York: Academic Press.

Goodwin, T. W. 1967. Terpenoids and chloroplast development. In Biochemistry of Chloroplasts (Edited by T. W. Goodwin), pp. 721-733, New York: Academic Press.

Goodwin, T. W. 1959. Stereospecific studies on carotenoid biosynthes is. Pure App 1. Chem. 20:483-496.

Goodwin, T. W. and Jamikorn, M. 1952. Biosynthes is of carotenes in ripening tomatoes. Nature 170:104-105.

Goodwir, T. W. and Williams, R. J. H. 1965. A mechanism for the biosynthes is of $\alpha$-carotene. Biochem. J. $97: 28 c-32 c$.

Griffiths, M., Sistrom, W. R., Cohen-Bazire, G. and Stanier, R: Y. 1955. Function of carotenoids in photosynthesis. Nature 176:1211-1215.

Griffiths 14 W. T., Thre $f$ fal1, D. R. and Goodwin, T. W. . 1964. Incorporation of ${ }^{4} \mathrm{CO}_{2}$ and $\left[2-{ }^{4} \mathrm{C}\right]$ mevalonic acid into plastoquinone in maize and barley seedlings. Biochem. J. 90:40p-4lp.

Habermann, H. M. 1960. Spectra of normal and pigment-deficient mutant leaves of Helianthus annuus L. Physiol. Plant. 13:718-725.

Harris, W. M. and Spurr, A. R. 1969a. Chromoplasts of tomato fruits. I. Ultrastructure of low-pigment and high-beta mutants. Carotene. analyses. Amer. J. Bot. 56:369-379.

Harris, W. M. and Spurr, A. R. 1969b. Chromoplasts of tomato fruits. II. The red tomato. Amer. J. Bot. 56:380-389.

Hill, H. M. and Rogers, L. J. 1969. Conversion of lycopene into B-carotene by chloroplasts of higher plants. Biochem. J. 113:37p-32p. 
Howes, C. D. and Batra, P. P. 1970. Accumulation of Tycopene and inhibition of cyclic caroterioids in Mycobacterium in the presence of nicotine. Biochim. Biophys. Acta 222:174-179.

Isler, 0. von, Chopard-dit-Jean, L. H., Montavon, M., Ruegg, R. und Zelier, P. 1957. Synthesen in der Carotinoid-Reihe. 12. Mitt. Synthese von $11,17^{\prime}-$ Di-cis- - -Carotin nach einem neuen Auftauprinzip. Helv. Chim. Acta $40: 1256-1262$.

Jenkins, J. A. and Mackinney, G. 1955. Carotenoids of the apricot tomato and its hybrids with yellow and tangerine. Genetics 40:715-721.

Jungalwala, F. B. and Porter, J. W. 1965. The configuration of phytcene. Arch. Biochem. Biophys, 110:291-299.

Jungalwala, F. B. and Porter, J. W. 1967. Biosynthies is of phytoene from isopenteny] and farnesyl py'rophosphates by a partially purified tomato enzyme system. Arch. Biochem. Biophys. 119:209-219.

Karg7, T. E., Quackenbush, F. W. and Tomes, M. L. 1960. The carotenepolyene system in a strain of tomatoes high in delta-carotene and its comparison with eight other tomato strains. Proc. Amer. Soc. Hort. Sci. $75: 574-578$.

Khudairi, A. K. and Arboleda, O. P. 1971. Phytochrome-inediated carotenoid biosynthesis and its influence by plant hormones. Physiol. Plant. $24: 18-22$.

Kirk, J. T. 0. and Tilney-Bassett, R. A. E. 1967. The Plastids. Their Chemistry, Structure, Growth and Inheritance. San Francisco: W. H. Freeman and Co.

Knypl, J. S. 1969. Accumulation of lycopene in detached cotyledons of pumpkin. Naturwiss. 55:572.

Kohler, G. W., Lincoln, R. E., Porter, J. W., Zscheile, F. P., Caldwe11, R. M., Harper, R. H. and Silver, W. 1947. Selection and breeding for high 6 -carotene content (provitamin A) in tomato. Bot. Gaz. $109: 219-225$.

Koski, V. M. and Smith, J.H. C. 1951. Chlorophyll formation in a mutant white maize seedling-3. Arch. Biochem. Biophys. 34:189-194.

Krinsky, N. I. 1966. The role of carotenoid pigments as protective agents against photosensitized oxidations in chloroplasts. In Biochemistry of Chloroplasts (Edited by T.W. Goodwin): pp. 423-430, New York: $\overline{A c a}$ demic Press. 
Krinsky, N. I. 1968. The protective function of carotenoid pigments. Photophysio. 3:123-195.

Kushwaha, S., Subbarayan, C., Beeler, D. A. and Porter, J. W. 1969. The conversion of lycopene-15,15'- $\mathrm{H}$ to cyclic carotenes by soluble extracts of higher plant plastids. J. Biol. Chem. 244:36:35-3642.

Lascelles, J. 1965. The biosynthesis of chlorophy11. In Biosynthetic Pathways in Higher Plants (Edited by J. B. Pridham and T. Swain), pp. 163-177, New York: Academic Press.

Lee, T. C. and Chichester, C. 0. 1969. Geranyigeranyl pyrophosphate as the condensing unit for enzymic synthes is of carotenes. Priytochem. 8:603-609.

Lefort, M. 1957. Structure inframicroscopique des chloroplastes des certains mutants depigmentees chez Lycopersicum esculentum. Compt. Rendu Acad. Sci. (Paris) 245:718-720.

LeRosen, A. L., Went, F.W. and Zechmeister, L. 1941. Relation between genes and carotenoids of the tonato. Proc. Nat. Acad. U. S. 27: $236-242$.

LeRosen, A. L. and Zechmeister, L. 1942. Prolycopene. J. Amer. Chem. Soc. $64: 1075-1079$.

Lichtenthaler, H. K. and Becker, K. 1970. Inhibition of the light-induced vitamin $K_{1}$ and pigment synthes is by abscisic acid. Phytochem. 9: 2109-2113.

Lincoln, R. E, and Porter, J. W. 1950. Inheritance of $\beta$-carotene in tomatoes. Genetics $35: 206-211$.

Mackinney, G. and Jenkins, U. A. 1949. Inheritance of carotenoid differences in Lycopersicon esculentum strains. Proc. Nat. Acad. Sci. U. S. $35: 284-291$.

Mackinney, G. and Jenkins, J. A. 1952. Carotenoid differences in tomatoes. Proc. Nat. Acad. Sci. U. S. 38:48-52.

Mackinney, G., Rick, C. M. and Jenkins, J. A. 1956. The phytoene content of tomatoes. Proc. Nat. Acad. Sci. U. S. 42:404-408.

Malhotra, H. C., Britton, G. and Goodwin, T. W. i970. A novel series of 1,2-dihydro carotenoids. Internat. J. Vit. Res. 40:315-322. 
Mathews, M. M. 1964. The effect of 10 w temperature on the protection by carotenoids against photosensitization in Sarcina lutea. Photochem. Photobiol. 3:75-77.

Mathews-Roth, M. M. and Krinsky, N. I. 1970a. Failure of carotenoids to protect a mutant. Photochem. Photobial. 11:555-557.

Mathews-Roth, M. M. and Krinsky, N. I. 1970b. Carotenoid pigments and the stability of the cell membrane of Sarcina lutea. Biochim. Biophys. Acta 203:357-359.

Mathews-Roth, M. M. and Krinsky, N. I. 19\%c. Studies on the protective function of carotenoid pigments of Sarcina lutea. Photochem. Photobiol. 11:419-428.

Mathews, M. M. and Sistrom, W. R. 1959. Function of carotenoid pigments in non-photosynthetic bacteria. Nature 184:1892-1893.

Meissner, G. and Delbruck, M. 1968. Carotenes and retinãl in Phycomyces mutants. Plant Physiol. 43:1279-1283.

Mercer, E. I. afd Goodwin, T. W. 1962. The incorporation of $\left[2{ }^{14} \mathrm{C}\right]$ mevalonic acid and ${ }^{14} \mathrm{CO}$ into the phytyl side chain of chlorophy 11 in maize seedlings. Bfochem. J. $85: 13 p$.

Mercer, E. I. and Goodwin, T.W. 1963. Incorporation of $\left[2-{ }^{14} \mathrm{C}\right]$ mevalonic acid into sterols of maize seedlings. Biochem. J. 88:46p-47p.

Mercer, E. I. and Pughe, J. E. 1969. The effects of abscisic acid on the biosynthesis of isoprenoid compounds in maize. Phytochem. 8:115122.

Pauling. L. 1939. Recent work on the configuration and electronic structure of molecules; with some applications to natural products. Fortschr. Chem. organ. Naturstoffe 3:203-235.

Porter, J. W. 1969. Enzymatic synthesis of carotenes and related compounds. Pure Appl. Chem. 20:449-481.

Porter, J. W. and Anderson, D. G. 1962. The biosynthesis of carotenes. Arch. Biochem. Biophys. 97:520-528.

Porter, J. W. and Anderson, D. G. 1967. Biosynthesis of caroteres. Ann. Rev. Plant Physiol. 18:197-228. 
Porter, J. W. and Lincoin, R. E. 1950. I. Lycopersicon selections containing a high content of carotenes and colorless polyenes. II. The mechanism of carotene biosynthesis. Arch. Biochem. Biophys. 27:390-403.

Porter, J. W. and Zscheile, F. P. 1946. Carotenes of Lycopersicon species and strains. Arch. Biochem. 10:537-545.

Rau, W. und Zehender, C. 1959. Die Carotinoide von Fusarium aquaeductum Lagh. Arch. Mikrobiol. 32:423-4.28.

Raymundo, L. C., Griffiths, A. E. and Simpson, K. L. 1967. Effect of dimetinyl sulfoxide (DMSO) on the biosynthesis of carotenoids in detached tomatoes. Phytochem. 6:1527-1532.

Raymundo, L. C., Griffiths, A. E. and Simpson, K. L. 1970. Biosynthesis of carotenoids in the tomato fruit. Priytochem. 9:12391245.

Rick, C. M.: Thompson, A. E. and Brauer, 0. 1959. Genetics and development of an unstable chlorophyil deficiency in Lycopersicon esculentum. Amer. J. Bot. 46:1-11.

Rilling, H. C. 1962. Anaerobic carotenoid synthesis by an aerobic microorganism. Biochim. Biophys. Acta 55:156-158.

Rogers, L. J., Shah, S. P. J. and Goodwin, T. W. 1956. Intracellular localization of mevalonate-activating enzyme in plant cells. Biochem. J. $99: 381-388$.

Rogers, L. J., Shah, S. P. J. and Goodwin, T. W. 1967. The intracelluiar localization of mevalonate activating enzymes: Its importance in the regulation of terpenoid biosynthesis. In Biochemistry of Chloroplasts (Edited by T. W. Goodwin), pp 282292, Heiv York: Acadernic Press.

Rosso, S. W. 1967. An ultrastructural study of the mature chromoplasts of the tangerine tomato (Lycopersiron esculentum var. "Golden Jubilee"). J. U1 trastr. Res. 20:179-189.

Rosso, S. W. 1968. The ultrastructure of chromoplast development in red tomatces. J. U1trastr. Res. 25:307-322.

Sander, C., Laber, L. J., Bel1, H. G. and Hamilton, R. H. 1968. Light sensitivity of plastids and plastid pigments in the albescent maize mutant. Plant Physiol. 43:693-697. 
Schroeder, W. A. 1942. Formation of pro-carotenoids in "monkey flowers" under some conditions. J. Amer. Chem. Soc. 64:2510-2511.

Shah, D. V., Feldbruegge, D. H., Houser, A. R. and Porter, J. W. 1968. Conversion of ${ }^{4} C$-labeled geranylgeranyl pyrophosphate to phytoene by a soluble tomato plastid enzyme system. Arch. Biochem. Biophys. $127: 124-131$.

Simpson, K. L., Nakayama, T. 0. M. and Chichester, C. 0. 1954. Biosynthes is of yeast carotenoids. J. Bacteriol. 88:1688-1694.

Smith, J. H. C., Durham, L. J. and Wurster, C. F. 1959. Formation and bleaching of chlorophyll in albino corn seedlings. Plant Physiol. $34: 340-344$.

Spikes, J. D. and Straight, R. 1967. Sensitized photochemical processes in biological systems. Ann. Rev. Phys. Chem. 18:409-436.

Subbarayan, C., Kushwaha, S. C., Suzue, G. and Porter, J. 1970. Enzymatic conversion of isopenteriyl pyrophosphate-4- ${ }^{4} \mathrm{C}$ and phytoene${ }^{1} \mathrm{C}$ to acyclic carotenes by an ammonium sulfate-precipitated spinach enzyme system. Arch. Biochem. Biophys. 137:547-557.

Suzue, G. 1961. Enzymatic conversion of bacterial phytoene into $\delta$-carotene. Biochim. Biophys. Acta 50:593-594.

Taylor, F. H. and Burden, R. S. 1970. Identification of plant growth inhibitors produced by photolys is of violaxantinin. Phytochem. 9: 2217-2223.

Taylor, H. F. and Smith, T. A. 1967. Production of plant growth inhibitors from xanthophylls: a possible source of dormin: Nature 215:1513-1514.

Thompson, A. E., Tomes, M. L., Wann, E. V., McCollum, J. P. and Stoner, A. K. 1965. Characterization of crimson tomato fruit color. Proc. Amer. Soc. Hort. Sci . 86:610-616.

Tomes, M. L. 1963. Temperature inhibition of carotene synthesis in tomato. Bot. Gaz. 124:180-185.

Tomes, M. L. 1964. The function and specificity of the B (beta-carotene) and Del (delta-carotene) factors in the tomato. Genetics 50:291.

Tomes, M. L. 1967. The comparative effect of the beta- and deltacarotene genes on alpha- or beta-ionone ring formation in the tomato. Genetics 56:227-232. 
Tomes, H. L. 1969. Delta-carotene in the tomato. Genetics 62:769-780.

Tomes, M. L., Quackenbush, F. W. and Karg1, T. E. 1956. Action of the gene $B$ in the biosynthes is of carotenes in the tomato. Bot. Gaz. $117: 248-253$.

Tomes, M. L., Quackenbush, F. W. and Kargl, T. E. 1958. Synthes is of Bcarotene in the tomato fruit. Bot. Gaz. 119:250-253.

Tomes, M. L., Quackenbush, F. W. and McQuistan, M. 1954. Modification and dominance of the gene governing formation of high concentrations of beta-carotene in the tomato. Genetics 39:810-817.

Tomes, M. L., Quackentish, F. Ki., Nelson, O. E. and North, B. 1953. The inheritance of carotenoid pigment systems in. the tomato. Genetics $38: 116-127$.

Treharne, 1 . J., Mercer, E. I. and Goodwin, T. W. 1964. Incorporation of [2- ${ }^{4} \mathrm{C}$ ]mevalonic acid lactone and ${ }^{4} \mathrm{CO}$ into sterol, $\beta$-carotene and phyto i in developing leaves of monocotbledonous and dicotyledonous plants. Biochem. J. 90:39p-40p.

Treharpe, K. J., Merqer, E. I. and Goodwin, T. W. 1966. Incorporation of ${ }^{4} \mathrm{CO}_{2}$ and $\left[2-{ }^{4} \mathrm{C}\right]$ mevalonic acid into terpenols of higher plants during chlopoplast development. Biochem. J. 239-245.

Varma, T. N. R. and Chichester, C. 0. 1962. Ineorporation of $\Delta^{3}$-isopentenyl pyrophosphate into lycopene in tonato homogenate. Arch. Biochem. Biophys. $96: 255-269$.

Wallace, R. H. and Habermann, H. M. 1959. Genetic history and general comparisons of two albino mutations of Helianthus annuus. Amer. J. But. 46:157-162.

Wallace, R. H. and Schwarting, A. E. 1954. A study of chlorophyll in a white mutart strain of Helianthus annuus. Plant Physiol. 29:431436 .

Walles, B. 1963. Macromolecular physiology of plastids. IV. On amino acid requirements of lethal chloroplas $\tau$ mutants in barley. Hereditas $50: 317-344$.

Walles, B. 1965. Plastid structures of carotenoid-deficient mutants of sunflower (Helianthus annuus L.). I. The white mutant. Hereditas $35: 247-256$. 
Walles, B. 1966. Plastid structures of carotenoid-deficient mutants of sunflower (Helianthus annuus L.). II. The yellow mutant. Hereditas $56: 131-136$.

Walles, B. 1967. Use of biochemical mutants in analyses of chloroplast morphogenesis. In Biochemistry of Chloroplasts (Edited by T.W. Goodwin), pp. 633-653, New York: Academic Press.

Wareing, P. F., El-Antably, H. M. M., Good, J. and Manuel, J. 1967. Wachstumregulatoren bei Pflanzen. Intenat. Vortragstagung, p. 667, Verlag Universitat Rostock.

Wells, L. W., Schelble, W. J. and Porter, J.W. 1964. The enzymic synthesis of carotenes by isolated tomato fruit plastids and spinach leaf chloroplasts. Federation Proc. 23:426.

Williams, R. J. H., Britton, G., Charlton, J. M. and Goodwin, T. W. 1967. The stereospecific biosynthesis of phytoene and polyunsaturated carotenes. Biochem. J. 104:767-777.

Williams, R. J. H., Britton, G. and Goodwin, T.W. 1957. The biosynthesis of cyclic aarotenes. Biochem. J. 105:99-105.

Wright, L. J. and Rilling, H. C. 1963. The function of carotenoids in a photochromogenic bacterium. Photochem. Photobiol, 2:339-342.

Yamarioto, H. Y. and Chichester, C. 0. 1965. Dark incorporation of ${ }^{18} \mathrm{O}_{2}$ into antheraxanthin by bean leaf. Biochim. Biophys. Acta 109:303-305?

Yamamoto. H. Y., Nakayama, T. 0. M. and Chichester, C. 0. 1962. Studies on the light and dark interconversions of leaf xanthophylls. Arch. Biochem. Biophys. 97:168-173.

Zechmeister, L. 1963. cis-trans Isomeric Carotenoids, Vitamin A and Arylpolyenes. Vienna: Springer-Verlag.

Zechmeister, L., LeRosen, A. L., Went, F. W. and Pauling. L. 1941. Prolycopene, a naturaliy occurring stereoisomer of lycopene. Proc. Nat. Acad. Sci. U. S. $27: 468-474$.

Zechmeister, L. and Went, F.W. 1948. Some stereo-chemical aspects in genetics. Nature 162:847-848.

Zscheile, F. P., Jr. and Lesley, J.W. 1967. Pigment analysis of sherry flesh color mutation resembling yellow in the tomato. J. Heredity $58: 193-194$. 